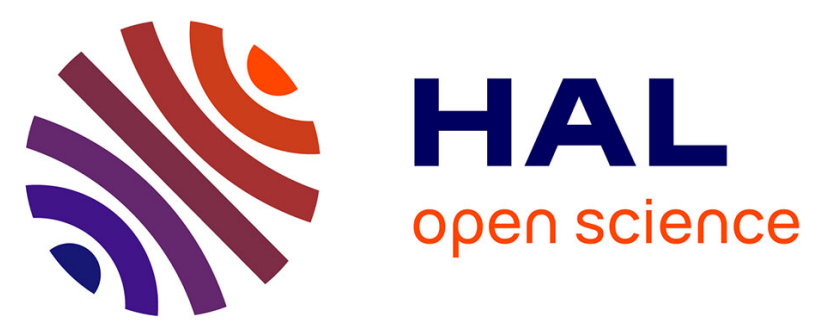

\title{
Interaction between the SH3 domain of Src family kinases and HTLV-1 p13's proline rich motif: a novel mechanism underlying delivery of Src family kinases to mitochondria
}

\author{
Elena Tibaldi, Andrea Venerando, Francesca Zonta, Carlo Bidoia, Elisa \\ Magrin, Oriano Marin, Antonio Toninello, Luciana Bordin, Veronica Martini, \\ Mario A Pagano, et al.
}

\section{- To cite this version:}

Elena Tibaldi, Andrea Venerando, Francesca Zonta, Carlo Bidoia, Elisa Magrin, et al.. Interaction between the SH3 domain of Src family kinases and HTLV-1 p13's proline rich motif: a novel mechanism underlying delivery of Src family kinases to mitochondria. Biochemical Journal, 2011, 439 (3), pp.505516. 10.1042/BJ20101650 . hal-00633603

\section{HAL Id: hal-00633603 https://hal.science/hal-00633603}

Submitted on 19 Oct 2011

HAL is a multi-disciplinary open access archive for the deposit and dissemination of scientific research documents, whether they are published or not. The documents may come from teaching and research institutions in France or abroad, or from public or private research centers.
L'archive ouverte pluridisciplinaire HAL, est destinée au dépôt et à la diffusion de documents scientifiques de niveau recherche, publiés ou non, émanant des établissements d'enseignement et de recherche français ou étrangers, des laboratoires publics ou privés. 
Interaction between the SH3 domain of Src family kinases and HTLV-1 p13's proline rich motif: a novel mechanism underlying delivery of Src family kinases to mitochondria

Elena Tibaldi ${ }^{*}$, Andrea Venerando ${ }^{* \dagger}$, Francesca Zonta ${ }^{*}$, Carlo Bidoia ${ }^{\ddagger}$, Elisa Magrin*, Oriano Marin ${ }^{*}$, Antonio Toninello*, Luciana Bordin", Veronica Martini ${ }^{\dagger}$, Mario Angelo Pagano ${ }^{* 1}$ and Anna Maria Brunati ${ }^{* 1,2}$

*Department of Biological Chemistry, University of Padua, Viale G. Colombo 3, 35131 Padua, Italy,

†Venetian Institute of Molecular Medicine (VIMM), Via G. Orus, 2, 35129 Padua, Italy

Centre for Research in Infectious Diseases, School of Medicine and Medical Science,

University College Dublin, Belfield. Dublin 4, Ireland

${ }^{1}$ These authors are co-senior authors.

${ }^{2}$ Corresponding author:

Anna Maria Brunati

Department of Biological Chemistry, University of Padua, Viale G. Colombo 3, 35131, Padua, Italy,

Tel: +39-049-8276114

Fax: +39-049-8073310

E-mail: annamaria.brunati@unipd.it 


\begin{abstract}
Synopsis
The association of the SH3 domain of Src Family Kinases (SFKs) with protein partners bearing proline rich motifs has been implicated in the regulation of the activity, and recently described as a possible mechanism of relocalization to subcellular compartments, of SFKs.

We demonstrate for the first time that $\mathrm{p} 13$, an accessory protein encoded by the Human T-cell Leukemia Virus type 1 (HTLV-1), binds the SH3 domain of SFKs via its C-terminal proline rich motif, forming a stable heterodimer that translocates to mitochondria by virtue of its $\mathrm{N}$-terminal mitochondrial localization signal. As a result, the activity of SFKs is dramatically enhanced with subsequent increase in mitochondrial tyrosine phosphorylation and the recognized p13's ability to insert itself into the inner mitochondrial membrane and to perturb the mitochondrial membrane potential is abolished.

Overall, this study, in addition to confirming that the catalytic activity of SFKs is modulated by interactors of their SH3 domain, lead us to hypothesize a general mechanism by which proteins bearing a proline rich motif and a mitochondrial localization signal at the same time may act as carriers of SFKs into mitochondria, thus contributing to regulate mitochondrial functions under various pathophysiological conditions.
\end{abstract}

Keywords: SFKs, mitochondria, HTLV-1 p13, SH3 domain.

Running Title: HTLV-1 p13 targets SFKs to mitochondria 


\section{Introduction}

Src Family Kinases (SFKs) are non-receptor tyrosine kinases acting as molecular switches generally described associated with the inner face of the plasma membrane, integrating diverse signals generated by the cell surface receptors in response to a large number of extracellular cues, regulating a variety of cellular events, such as cell growth and proliferation, cell adhesion and migration, differentiation, survival, and death [1-3]. In the last decade, SFKs have been reported to target other subcellular compartments, such as endosomes, secretory granules, or phagosomes, the endoplasmic reticulum, the Golgi apparatus and mitochondria [4-9]. Although distinctive localizations of SFK members have been implicated in their specific functions, the mechanism of localization and their function exerted in these organelles still remain to be determined. SFKs comprise eight members classed into two groups on the basis of the phylogenetic tree inferred from the analysis of the complete sequence of each kinase [10], namely Src related (Src, Yes, Fyn and Fgr) and Lyn related SFKs (Lyn, Hck, Lck and Blk). SFKs possess a common modular structure consisting of i) an SH4 domain, a unique N-terminal sequence for myristoylation and/or palmitoylation, ii) an SH3 domain, which associates with specific proline rich sequences, iii) an $\mathrm{SH} 2$ domain which recognizes phosphotyrosine motifs, and iv) a kinase domain, also referred to as SH1 domain, followed by a C-terminal tail playing a negative regulatory role when phosphorylated by the inhibitory c-Src tyrosine kinase (CSK) [11]. SFKs are ordinarily kept in a closed inactive conformation through two major intramolecular inhibitory interactions, namely the binding of the C-terminal CSK-phosphorylated tyrosine (i.e. Tyr527 of c-Src) to the SH2 domain, and the interaction of a polyproline type II helical motif (PPII, containing the core consensus sequence Pro-X-X-Pro, where Pro stands for proline residue and $\mathrm{X}$ for any amino acid) within the SH2-kinase linker with the SH3 domain $[12,13]$. Conformational transition from the inactive to the active form of SFKs is induced by an array of factors including physiologycal and pathological stimuli triggering dephosphorylation of the Cterminal tail by several tyrosine phosphatases, and displacement of the SH2 or SH3 domains by specific ligands that lead to the disruption of the inhibitory intramolecular interactions, these events occurring singly, sequentially or synergistically [14-20]. Importantly, the open active form of SFKs is in turn susceptible to recognition by interacting proteins capable of engaging the non-catalytic domains, resulting in modulation of SFK activity $[3,11]$.

The complex regulation of SFK activity is well exemplified by the specific binding of the SH3 domain to ligands displaying a proline-rich motif, which, based upon the activation state of SFKs and the type of interactors, can be a mechanism of activation or inhibition of SFKs themselves $[3,11]$. In fact, while the HIV accessory protein Nef was the first molecule shown to elicit the SFK activity through this mode of interaction [18], followed by other viral [21-24] and cellular proteins [25-29] all of them bearing a proline rich motif, p66 ${ }^{\text {shc }}$ has recently been described to interact with the active form of SFKs and initiate inhibition thereof through a proline rich motif/SH3 interaction [30]. Emerging evidence indicates that, in addition to the prevailing view of a regulating role on the kinase activity, this type of interaction can influence the turnover of these kinases [31] and/or their localization in various subcellular compartments [27, 32]. Recently, we have demonstrated that Lyn, is not only found to be resident in the intermembrane space of mitochondria [33] but also can be remarkably translocated from the plasma membrane to these organelles in the early phases of liver regeneration, taking part in a multiprotein complex, ultimately preserving mitochondrial integrity.

The aim of this study was to assess whether SFKs can traffic to mitochondria through the assembly with proteins known to be imported into mitochondria and containing a proline-rich motif putatively capable of binding SH3 domains. In this regard, the Human T-cell Leukemia Virus type 1 (HTLV-1) accessory protein p13 fulfilled the above criteria, being targeted to mitochondria and possessing a well-defined C-terminal proline rich motif [34]. Here, we demonstrate that the interaction between $\mathrm{p} 13$ and distinct SFKs dramatically activates SFK activity and results in the import of SFKs into mitochondria. Intriguingly, p13's recognized capability of triggering an inward $\mathrm{K}^{+}$current leading to swelling, depolarization and increased 
respiratory chain activity in mitochondria [34] is strongly impaired by the SH3-dependent assembly with SFKs, supporting the notion of a scaffolding function of this family of protein kinases and disclosing novel insights into the action exerted by p13 in HTLV-1 infected cells.

\section{Experimental}

\section{Materials}

All analytical grade reagents, cell culture media, and Phosphatase Inhibitor Cocktail 2 and 3 were from Sigma-Aldrich (St. Louis, MO). $\left[\gamma_{-}{ }^{33} \mathrm{P}\right] \mathrm{ATP}(3000 \mathrm{Ci} / \mathrm{mmol})$ was purchased from PerkinElmer (Waltham, MA). Anti-Lyn (sc-15), anti-Src (sc-19), anti-Fyn (sc-434), anti-Fgr (sc130) and anti-TOM20 rabbit polyclonal FL-145 (sc-11415) (anti-TOM20 R) and F-10 mouse monoclonal (sc-17764) (anti-TOM20 M), respectively, antibodies were from Santa Cruz Biotechnology (Heidelberg, Germany). The monoclonal anti-phosphotyrosine (p-Tyr) antibody (clone PY-20) was from BioSource International (Invitrogen, Paisley, UK). Anti-aconitase (ab102803), anti-apoptosis inducing factor (AIF) (ab1998) and anti-lactate dehydrogenase (LDH) (ab52488) antibodies were from Abcam (Cambridge, UK). Complete Protease Inhibitor Cocktail Tablets and anti-c-myc antibody (clone 9E10) were from Roche Diagnostics (Mannheim, Germany). Anti-phosphoSFK (anti-Src pY416) antibody was from Cell Signaling Technology (Danvers, MA). 4-Amino-5-(4-chlorophenyl)-7-(t-butyl)pyrazolo[3,4-d]pyrimidine (PP2) as well as horseradish peroxidase (HRP)-conjugated antibodies were purchased from Calbiochem (Merck KGaA, Darmstadt, Germany). The enhanced chemiluminescence (ECL) detection system was from GE Healthcare (Milan, Italy).

\section{Methods}

\section{Peptide synthesis, production and purification of anti-p13 antibody}

The full length form of wild type p13, the p13-derived peptide covering the N-terminal region (p13[9-41]), and the p13-derived peptide covering the C-terminal proline-rich motif (p13[61-87]) were synthesized by solid phase peptide synthesis as described in [35]. The anti-p13 antibody was raised against p13 in New Zealand rabbits and purified by affinity chromatography after immobilization of p13 on Sulfo Link Coupling Gel (Pierce, UK), according to the manufacturer's instructions. The antigenicity of full length wild type p13 and the $\mathrm{N}$ - and Cterminal regions of p13 itself was tested by dot blot analysis.

\section{Dot blot analysis}

Increasing quantities (from $10 \mathrm{ng}$ to $10 \mu \mathrm{g}$ ) of full length synthetic p13, N-terminal p13-derived peptide [9-41] or C-terminal p13-derived peptide [61-87] were spotted onto nitrocellulose membranes. The membranes were blocked with $3 \%(\mathrm{w} / \mathrm{v})$ bovine serum albumin (BSA) in a Tris-Buffer Saline (TBS) solution $(50 \mathrm{mM}$ Tris, $\mathrm{pH} 7.5,150 \mathrm{mM} \mathrm{NaCl}$ ) for $1 \mathrm{~h}$ at room temperature (RT), incubated with the anti-p13 antibody (1:500 or 1:2000 dilution) for $2 \mathrm{~h}$ at RT, washed three times with TBS supplemented with $0.1 \%(\mathrm{v} / \mathrm{v})$ Tween-20 (TBST), and then incubated with HRP-conjugated anti-rabbit antibody (1:5000) in TBS at RT for $30 \mathrm{~min}$. Membranes were washed three times with TBST, and developed using the ECL detection system, captured using a Kodak Image Station 2000R and visualized by a Kodak 1D Image software (Eastman Kodak Co., New Haven, CT).

\section{Far western blotting}

$0.1 \mu \mathrm{g}$ of Src purified from rat brain according to [36], $0.1 \mu \mathrm{g}$ of Fyn, Fgr, and Lyn, respectively, purified from rat spleen according to [9], and $0.1 \mu \mathrm{g}$ of BSA, as negative control, were subjected to sodium dodecyl sulfate-polyacrylamide gel electrophoresis (SDS-PAGE) and blotted onto 
nitrocellulose membranes. The membranes were blocked by $3 \%(\mathrm{w} / \mathrm{v})$ BSA in TBS and then incubated in a buffer containing $20 \mathrm{mM}$ Tris/ $\mathrm{HCl} \mathrm{pH} \mathrm{7.5,} 300 \mathrm{mM} \mathrm{KCl,} 0.1 \%$ (v/v) Tween-20 for $30 \mathrm{~min}$ at $4{ }^{\circ} \mathrm{C}$. Synthetic full length p13 $(30 \mu \mathrm{g} / \mathrm{ml})$ was then overlaid for $2 \mathrm{~h}$ at $20^{\circ} \mathrm{C}$ in the absence or presence of p13[61-87], and probed with anti-p13 antibody. After washing with TBST, the membranes were incubated with HRP-conjugated polyclonal antibody for $1 \mathrm{~h}$. Immunoblots were developed by the ECL detection system, captured using the Kodak Image Station 2000R and visualized by the Kodak 1D Image software).

\section{Western blot analysis}

Samples were rapidly solubilized in $62 \mathrm{mM}$ Tris/ $\mathrm{HCl}$ buffer, $\mathrm{pH} 6.8$, containing $5 \%(\mathrm{v} / \mathrm{v})$ glycerol, $0.5 \%(\mathrm{v} / \mathrm{v}) 2$-mercaptoethanol and $0.5 \%(\mathrm{w} / \mathrm{v})$ SDS (SDS buffer) and subjected to SDSPAGE before being transferred onto nitrocellulose membranes by electroblotting. After treatment with $3 \%(\mathrm{w} / \mathrm{v}) \mathrm{BSA}$ in TBS at $4{ }^{\circ} \mathrm{C}$ overnight, membranes were incubated for $2 \mathrm{~h}$ with primary antibodies (anti-Lyn, anti-Src, anti-Fyn and anti-Fgr antibodies diluted 1:400; anti-pTyr, anti-aconitase, anti-AIF and anti-LDH antibodies diluted 1:1000). After washing with TBST, the membranes were incubated with secondary HRP-conjugated polyclonal antibody for $1 \mathrm{~h}$. Immunoblots were developed using the ECL detection system. Images were captured using the Kodak Image Station 2000R and visualized by the Kodak 1D Image software. Loading controls were performed by re-probing membranes with appropriate antibodies after stripping twice in $0.1 \mathrm{M}$ glycine, $\mathrm{pH} 2.5,0.5 \mathrm{M} \mathrm{NaCl}, 0.1 \%(\mathrm{v} / \mathrm{v})$ Tween-20, 1\% (v/v) 2-mercaptoethanol and $0.1 \%(\mathrm{w} / \mathrm{v}) \mathrm{NaN}_{3}$, for $10 \mathrm{~min}$ each.

\section{Cell culture and transfection}

HeLa cells were maintained in Dulbecco Modified Eagle Medium (DMEM) supplemented with $10 \%$ fetal calf serum (FCS), 100 units $/ \mathrm{mL}$ penicillin, and 20 units $/ \mathrm{mL}$ streptomycin. The eukaryotic expression plasmids pcDNA3.1/myc-His C (empty vector) and pcDNA3.1/myc-His C/p13 (the latter containing the wild type p13 coding sequence), kindly provided by Luc Willems (Gembloux, Belgium), as well as pCMV6-XL4 (empty vector), pCMV6-XL4/Lyn (the latter containing the Lyn coding sequence) (OriGene Technologies, Rockville, MD), were used to perform transfection experiments, as described in [39]. Thirty-six hours after transfection, the medium was, when required, supplemented with $10 \mu \mathrm{M} \mathrm{PP} 2$, and the cells were further incubated for $12 \mathrm{~h}$ before being processed for distinct purposes as described in this Section.

\section{Immunoprecipitation}

p13 and the different SFKs were immunoprecipitated either as purified proteins in interaction assays, or from lysates of purified rat liver mitochondria or from mitochondrial lysates of transfected cultured cells. Immunoprecipitation was performed in the absence or presence of the recombinant Glutathione S-transferase (GST)-fusion form of the SH3 domain of Lyn (GST-Lyn SH3 domain), expressed and purified according to the protocol described in [31], or, when required, with p13[61-87] for $2 \mathrm{~h}$ at $4{ }^{\circ} \mathrm{C}$ with the appropriate antibodies in competition assays. The resulting immunocomplexes were recovered by incubation for $1 \mathrm{~h}$ with protein $\mathrm{A} / \mathrm{G}$ Sepharose previously saturated with BSA and washed three times with $50 \mathrm{mM}$ Tris/ $\mathrm{HCl}, \mathrm{pH} 7.5$, $1 \mathrm{mM}$ orthovanadate, phosphatase and protease inhibitor cocktails Samples were then subjected to Wsten blot analysis with the appropriate antibodies.

\section{Phosphorylation Assays}

Tyrosine kinase assays were performed in $40 \mu \mathrm{l}$ reaction mixture containing $50 \mathrm{mM}$ Tris/ $\mathrm{HCl}$, pH 7.5, $10 \mathrm{mM} \mathrm{MnCl} 2,30 \mu \mathrm{M} \mathrm{ATP} /\left[\gamma_{-}{ }^{33} \mathrm{P}\right] \mathrm{ATP}$ (specific activity $1000 \mathrm{cpm} / \mathrm{pmol}$ ), $100 \mu \mathrm{M}$ sodium orthovanadate, $200 \mu \mathrm{M} \operatorname{cdc} 2[6-20]$ peptide as substrate, and $20 \mathrm{ng}$ of Src, Fyn, Fgr or Lyn. Following incubation for $5 \mathrm{~min}$ at $30^{\circ} \mathrm{C}$, the reaction was blocked by adding $5 \mathrm{X}$ SDS buffer and the samples were subjected to SDS-PAGE. Peptide phosphorylation was evaluated using the Cyclone Plus Storage Phosphor System (Perkin Elmer). 


\section{Gel Filtration}

A Superdex 75 HR column (GE Healthcare, Milan, Italy) mounted on a fast performance liquid chromatography system was equilibrated with $20 \mathrm{mM}$ Tris- $\mathrm{HCl}, \mathrm{pH} 7.5,150 \mathrm{mM} \mathrm{NaCl}, 10 \%$ (v/v) glycerol, $10 \mathrm{mM} 2$-mercaptoethanol, and $50 \mu \mathrm{M}$ phenylmethylsulfonyl fluoride. The first $25 \mathrm{ml}$ were collected altogether, and then fractions of $0.2 \mathrm{ml}$ were collected at a flow rate of 0.4 $\mathrm{ml} / \mathrm{min}$.

\section{Preparation of mitochondria}

Rat liver mitochondria were prepared as described in [33]. Briefly, rat liver was homogenized in the isolation medium (250 mM sucrose, $5 \mathrm{mM}$ Hepes, $0.5 \mathrm{mM}$ EGTA, $\mathrm{pH} 7.4)$ and centrifuged at $900 \mathrm{~g}$ for $5 \mathrm{~min}$. The supernatant was centrifuged again at $12000 \mathrm{~g}$ for $10 \mathrm{~min}$ to precipitate a crude mitochondrial pellet. The pellet obtained was resuspended in an isolation medium plus 1 mM ATP and layered on top of a discontinuous gradient of Ficoll diluted in the isolation medium, composed of 2-ml layers of 16, 14, and 12\% (v/v) Ficoll and a 3-ml layer of 7\% Ficoll. After centrifugation for $30 \mathrm{~min}$ at $75000 \mathrm{~g}$, the mitochondrial pellet was suspended in the isolation medium and centrifuged again for $10 \mathrm{~min}$ at $12000 \mathrm{~g}$. The resulting pellet was suspended in the isolation medium without EGTA, and the protein content was measured by the biuret method, using BSA as standard. The absence of other contaminating subcellular compartments in the mitochondrial preparation has been demonstrated as described in [33].

\section{Treatment of isolated rat liver mitochondria with p13 and SFK}

p13 $(0.2 \mu \mathrm{g})$ was incubated with single SFKs $(0.1 \mu \mathrm{g})$ in the absence or presence of p13[61-87] or GST-Lyn SH3 domain for $2 \mathrm{~min}$ at $30{ }^{\circ} \mathrm{C}$ and subsequently incubated with $50 \mu \mathrm{g}$ of rat liver mitochondria re-suspended in $200 \mathrm{mM}$ sucrose, $10 \mathrm{mM}$ Hepes, $\mathrm{pH} 7.4,5 \mathrm{mM}$ succinate, 1.25 $\mu \mathrm{M}$ rotenone, $1 \mathrm{mM}$ sodium phosphate and protease inhibitors for $5 \mathrm{~min}$ at $30^{\circ} \mathrm{C}$.

The mitochondria were pelleted by centrifuging at $10000 \mathrm{~g}$ at $4{ }^{\circ} \mathrm{C}$ for $10 \mathrm{~min}$ and the reaction was stopped by washing twice with isolation medium.

\section{Proteinase K Treatment}

After treatment with p13 and/or SFKs, as described above, purified mitochondria were treated with $50 \mathrm{ng} / \mathrm{ml}$ proteinase $\mathrm{K}$ in the isolation medium without EGTA (see preparation of mitochondria) in the absence or presence of $0.5 \%(\mathrm{v} / \mathrm{v})$ Triton X-100 at room temperature for 30 min. The reaction was stopped by the addition of the protease inhibitor cocktail, and then analyzed by Western blotting with anti-p13, anti- Lyn, anti-aconitase and anti-AIF antibodies.

\section{Mitochondrial subfractionation}

To separate the mitochondrial membranes from the soluble fractions, $50 \mu \mathrm{g}$ of mitochondria, suspended in the isolation medium, were sonicated in an MSE Sonicator and subjected to eight freeze-thaw cycles. Mitochondrial suspensions were then ultracentrifuged at $100000 \mathrm{~g}$ for 30 min at $4{ }^{\circ} \mathrm{C}$ in a Beckman MLA-130 rotor.

\section{Digitonin treatment}

Purified mitochondria $(1 \mathrm{mg} / \mathrm{ml})$ were incubated with increasing concentrations of digitonin (from 0.1 to $0.6 \mathrm{mg} / \mathrm{ml}$ ) for $30 \mathrm{~min}$ at $4{ }^{\circ} \mathrm{C}$. The samples were then centrifuged at $22800 \mathrm{~g}$ for 20 min. Supernatant (S) and pellet (P) were subjected to SDS-PAGE and Western blotting analysis with the appropriate antibody.

\section{Determination of mitochondrial membrane potential $\left(\Delta \Psi_{\mathrm{m}}\right)$}

Membrane potential $\left(\Delta \Psi_{\mathrm{m}}\right)$ was measured by monitoring the distribution of the lipophilic cation tetraphenylphosphonium $\left(\mathrm{TPP}^{+}\right)$across the mitochondrial membrane with a selective electrode prepared in our laboratory according to published procedures [37] and an $\mathrm{Ag} / \mathrm{AgCl}$ reference 
electrode. $\mathrm{TPP}^{+}$was added at a final concentration of $2 \mu \mathrm{M}$ in order to achieve high sensitivity in measurements and to avoid toxic effects on the proton ATPase and on calcium movements. The membrane potential measured with the TPP + selective electrode was calibrated using the equation: $\Delta \Psi_{\mathrm{m}}=\left(\Delta \Psi_{\text {electrode }}-66.16 \mathrm{mV}\right) / 0.92$ as proposed in [38].

\section{Confocal microscopy}

HeLa cells were grown on $13 \mathrm{~mm}$ glass coverslips and transfected as above described. $48 \mathrm{~h}$ after transfection, cells were washed twice with PBS ( $1 \mathrm{mM} \mathrm{Na}_{2} \mathrm{HPO}_{4}, 1.8 \mathrm{mM} \mathrm{KH}_{2} \mathrm{PO}_{4}, 140 \mathrm{mM}$ $\mathrm{NaCl}$ and $2.7 \mathrm{mM} \mathrm{KCl}, \mathrm{pH} 7.4)$, fixed with $2 \%(\mathrm{w} / \mathrm{v})$ paraformaldehyde in PBS for 15 min at room temperature (RT), and then permeabilized with $0.2 \%(\mathrm{v} / \mathrm{v})$ Triton X-100 in PBS for 10 min at RT. Non-specific binding was prevented by the addition of 3\% BSA in PBS for 30 min. Then the cells were incubated for 1 hour at $37^{\circ} \mathrm{C}$ with the indicated primary antibodies supplemented with $1 \%(\mathrm{w} / \mathrm{v})$ BSA. After washing with PBS, the cells were incubated for $1 \mathrm{~h}$ at $37{ }^{\circ} \mathrm{C}$ with tetramethylrhodamine isothiocyanate (TRITC)-conjugated secondary antibody against rabbit IgG and fluorescein isothiocyanate (FITC)-conjugated secondary antibody against mouse IgG . After a final washing step with PBS, the coverslips were placed on to glass slides in FluorSave reagent $^{\mathrm{TM}}$ mounting medium (Calbiochem). Fluorescence was detected using an UltraView Living Cell Imaging (LCI) confocal system (Perkin Elmer, Waltham, MA, USA). FITC and TRITC were excited at 488 and $561 \mathrm{~nm}$, respectively, and emission was collected at 541 and 594 $\mathrm{nm}$, respectively. Final image composites were created using Adobe Photoshop 6.0.

\section{Statistical analysis}

Data are presented as mean $( \pm \mathrm{SD})$ and compared using 1 -way analysis of variance followed by Bonferroni post hoc test. A $P$ value less than 0.05 was considered statistically significant. All statistics were performed using GraphPad Prism (GraphPad Software, La Jolla, CA) statistical software.

\section{Results}

p13 interacts with SFKs and stimulates their activity via its $C$-terminal proline-rich region p13 is an 87-amino acid accessory protein of HTLV-1, the organization of which is shown in figure 1A. The primary structure of $\mathrm{p} 13$ contains a series of regions, including a proline rich motif (PRM) putatively capable of interacting with $\mathrm{SH} 3$ domains [34], albeit not fulfilling a canonical consensus, because of the absence of a basic amino acid residue upstream or downstream of the proline residues $[3,13]$.

To assess whether the C-terminal PRM of p13 was capable of interacting with the SH3 domain of SFKs, some of the members of SFKs, Src, Fyn, Fgr and Lyn, were run on SDS-PAGE and transferred onto nitrocellulose to undergo Far Western blot analysis. The immobilized enzymes were then incubated with $\mathrm{p} 13$ in the absence or presence of p13[61-87], a p13-derived peptide covering its C-terminal proline rich motif. As shown in Figure 1B, p13 was detected in the correspondence of all the SFKs tested (left panel), whereas this interaction was abolished by the presence of p13[61-87], indicating a competition with full length p13 and confirming the inability of the anti-p13 antibody to recognize the C-terminal region of p13 itself (Figure $\mathrm{S} 1$ ). To demonstrate that the SH3 domain of SFKs was implicated in the interaction with $\mathrm{p} 13$, and in particular with its C-terminal proline rich motif, p13 was incubated with the single SFKs (molar ratio 3:1) in the absence or presence of p13[61-87] or, alternatively, of the GST-Lyn SH3 domain (Figure 1C). By subsequent immunoprecipitation of p13 or the single SFKs and Western blot analysis with the respective antibodies, the presence of p13[61-87] or the GST-Lyn SH3 domain proved to prevent the formation of the SFK/p13 complex, confirming that this interaction was highly specific and mediated by the C-terminus of the viral protein and the SH3 
domain of the single SFKs tested. Under these experimental conditions, the residual quantity of SFKs in the supernatant after immunoprecipitating p13 alone was negligible, whereas p13 in the supernatant after immunoprecipitating SFKs was about 2/3 (data not shown).

Because a number of viral proteins containing a proline rich motif in their sequence have been shown to enhance SFK activity after engaging the SH3 domain of SFKs [11], we evaluated the ability of p13 to act as a positive regulator of SFKs. For this purpose, SFK activity was tested in vitro using the Src-specific peptide cdc2(6-20) as a substrate in the presence of increasing concentrations of full length p13 or p13[61-87], in the absence or presence of the GST-Lyn SH3 domain. Figure 2A shows that both p13 and p13[61-87] exerted an activatory effect on all the SFKs assayed in a dose-dependent manner, although the full length form of p13 was more potent in stimulating SFK activity even at much lower concentrations. On the other hand, the presence of the GST-Lyn SH3 domain blocked the increase in SFK activity due to the full length viral protein or its $\mathrm{C}$-terminal derived peptide, highlighting that the proline rich motif/SH3 domain interaction had a role in modulating SFK activity.

To assess the formation of the Lyn/p13 complex, we also performed size exclusion chromatography, showing that Lyn, detected at the molecular weight of about $60 \mathrm{kDa}$ when alone (Figure 2B, top panel), was eluted in the correspondence of about $75 \mathrm{kDa}$ when preincubated with $\mathrm{p} 13$, indicating that these two protein form a stable heterodimer with a 5 -fold increase in the enzyme activity (Figure $2 \mathrm{~B}$, middle panel). In contrast, the presence of the GSTLyn SH3 domain reversed the activatory effect by competing with Lyn's SH3 domain and hence disrupting the complex (Figure 2B, bottom panel). Similar data were obtained with Src, Fyn and Fgr (data not shown).

\section{SFKs traffic to mitochondria when complexed with $\mathbf{p} 13$}

p13 is known to mainly target mitochondria through an atypical N-terminal mitochondrial localization sequence (MLS), ${ }^{21}$ LRVWRLCTRRLVPHL ${ }^{35}$. This sequence is predicted to be part of an alpha-helix, the amphipathic properties of which are conferred by the four arginines, finally localizing to the mitochondrial inner membrane [34]. In contrast to other proteins bearing the canonical MLS, the targeting signal of p13 is not cleaved upon import into mitochondria [34]. After anchoring to the mitochondrial inner membrane, p13 has been recognized to trigger an influx of $\mathrm{K}^{+}$into the mitochondrial matrix accompanied by a concentration-dependent decrease in the mitochondrial inner membrane potential $\left(\Delta \Psi_{\mathrm{m}}\right)$ [35]. Since we demonstrated that $\mathrm{p} 13$ forms a stable heterodimer along with the SFKs examined, we evaluated the ability of p13 to act as a carrier for mitochondrial import of SFKs by virtue of its MLS. For this purpose, highly purified rat liver mitochondria (RLM), where we demonstrated that the protein level of SFKs is undetectable [33], were incubated with Src, Fyn, Fgr and Lyn, alternately, in the absence or presence of p13. After $5 \mathrm{~min}$ incubation, mitochondria were spun down and the resulting fractions, mitochondria $(\mathrm{M})$ and surnatant $(\mathrm{S})$ underwent Western blot analysis with antibodies against p13 and the single SFKs. As shown in Figure 3, Src and Lyn were found in the M fraction only after pre-incubation with p13 (lane 4 vs 6 , panel M), whereas they were totally recovered in the $S$ fraction when the sample was either devoid of p13 (lane 4 vs 6 , panel $S$ ) or pre-incubated with p13 in the presence of the GST-Lyn SH3 domain (lane 6 vs 7, M and S panels). Similar results were also achieved with the other SFKs examined, Fyn and Fgr (data not shown).

\section{The p13-SFK complex localizes to the intermembrane space of mitochondria}

To establish in which mitochondrial compartment p13 and SFKs were localized, RLM were incubated with p13 alone or in the presence of a slight molar excess of each tyrosine kinase available, and further processed as described below. Firstly, treatment with proteinase K evidenced susceptibility of p13 and Lyn to the protease only when mitochondria were solubilised with Triton X-100 (Figure 4A), indicating that p13 alone or in association with Lyn was localized inside mitochondria. Apoptosis-Inducing Factor (AIF), a structural component of the 
mitochondrial inner membrane, and aconitase, a mitochondrial matrix protein, were used as intramitochondrial markers. Secondly, after separation of mitochondrial membranes from the soluble fractions, as described in the Experimental section, p13 proved to be bound to the membrane fraction when incubated alone with mitochondria (Figure $4 \mathrm{~B}$, left panel), whereas it was found in the soluble fraction when complexed with Lyn (Figure 4B, right panel). Thirdly, treatment with increasing concentrations of digitonin resulted in a selective release of p13 depending on the absence or presence of Lyn. In particular, p13 was released from mitochondria, if previously incubated in the absence of Lyn, only at concentrations of digitonin higher than 0.4 $\mathrm{mg} / \mathrm{ml}$, similarly to AIF, which is suggestive of either a tight binding to the inner mitochondrial membrane or localization in the mitochondrial matrix; on the other hand, concentrations of digitonin as low as $0.1 \mathrm{mg} / \mathrm{ml}$ caused release of $\mathrm{p} 13$, if the latter was pre-incubated with Lyn, suggesting that this interaction prevented p13 from reaching the mitochondrial inner membrane, thus segregating it in the intermembrane space. Similar results were obtained using Src, the prototypical member of the Src-related group (Figure S2).

\section{Tyrosine phosphorylation in isolated mitochondria is induced by 13 -mediated import of SFKs}

To assess whether the association between SFKs and p13 could change Lyn's activity within mitochondria, as occurred in vitro, we incubated purified RLM in the presence of Lyn and p13, as previously described, and evaluated the level of mitochondrial tyrosine phosphorylation by Western blot analysis with anti-pTyr antibody.

Figure 5A shows a striking elevation in tyrosine phosphorylation of a number of mitochondrial proteins distributed over a wide range of molecular weights once Lyn translocated into mitochondria. The involvement of Lyn in this event was further confirmed by the effect of PP2, a specific SFK inhibitor (lane 6 vs 7, Figure 5A), and its activation was confirmed by Western blot analysis with the anti-Src pY416 antibody. To establish whether the level of tyrosine phosphorylation observed inside mitochondria was determined by the stability of the p13/Lyn complex, mitochondria pre-incubated with p13 and Lyn in the above conditions, were treated with $0.1 \mathrm{mg} / \mathrm{ml}$ digitonin. After centrifugation, the resulting supernatant was incubated in the presence of increasing concentrations of the GST-Lyn SH3 domain, subsequently subjected to immunoprecipitation with anti-p13 antibody and assayed for SFK activity. Figure 5C shows that the p13-Lyn interaction was still stable after translocation across the mitochondrial outer membrane, with a disruption of the complex occurring in a manner proportional to the concentration of the GST-Lyn SH3 domain (Figure 5B, left panel). Since the presence of the GST-Lyn SH3 domain blocked the stimulation of SFK activity due to p13, (Figure 5C), we presumed that the increase in SFK activity depended upon the stability of the p13/Lyn interaction. Similar findings were achieved for the other SFKs by examining Fyn, Fgr (data not shown) and Src (Figure S3).

\section{The interaction between $\mathrm{p} 13$ and SFKs impairs p13's ability to induce mitochondrial $\mathrm{K}^{+}$ influx}

p13 is known to target the inner mitochondrial membrane, bringing about substantial structural and functional changes of these organelles, such as fragmentation in a cellular context as well as increase in $\mathrm{K}^{+}$permeability. These effects result in depolarization of the inner mitochondrial membrane and enhancement of respiratory chain activity with concurrent elevation in production of ROS in isolated mitochondria [34]. Interestingly, we observed that p13 together with SFKs via a SH3/proline rich motif association in vitro formed a stable complex still capable of crossing the outer mitochondrial membrane of highly purified RLM, but that it was unable to insert itself into the inner mitochondrial membrane where it usually exerts its perturbing action (Figure 4). Therefore, we sought to verify whether the change in localization of p13 also affected the functional effects that it is known to provoke. For this purpose, rat liver mitochondria were tested for membrane potential $(\Delta \Psi \mathrm{m})$ before and after incubation with $\mathrm{p} 13$, the latter in turn mixed 
with either GST-Lyn SH3 or Lyn. Figure 6A shows that free p13 caused a sharp drop in $\Delta \Psi_{\mathrm{m}}$, as expected in accordance with the previously documented increase in the permeability of the inner mitochondrial membrane to small cations [35]. Conversely, when p13 was complexed with Lyn, its effect on $\Delta \Psi \mathrm{m}$ was dampened in a manner proportional to the molar ratios between the two proteins. In fact, decreasing p13/Lyn ratios as far as 1:1, as shown in Figure 6A, progressively abolished p13's capability of altering $\Delta \Psi \mathrm{m}$. Similar effects were obtained by using the GST-Lyn SH3 domain as a ligand for p13 (Figure 6B), indicating a role for the SH3 domain in affecting both function and localization of p13 itself. These findings also suggest a possible non-catalytic function of SFKs mediated by their SH3 domain.

\section{The p13/Lyn complex enters mitochondria in p13-transfected HeLa cells}

Once verified that p13 interacted with SFKs to form a complex capable of translocating to isolated mitochondria, we investigated the presence and the possible localization of such a complex also in living cells using Lyn- and p13-overexpressing cells. Among SFKs, we monitored Lyn expression because it has already been shown to translocate from the plasma membrane to mitochondria [33]. Therefore, HeLa cells were transfected with expression vectors for Lyn or p13 singly or in combination, or both empty vectors as a control, in the absence or in the presence of PP2, as described in the Experimental section. We examined the protein level of p13 and Lyn by Western blot analysis on the total cell lysate and on highly purified mitochondria obtained by protocols described in [33]. Figure 7A shows an increase in tyrosine phosphorylation in the whole cell lysate (left panel) upon transfection of Lyn (lane 3), as expected, and of p13 (lane 5), indicating that this latter was per se capable of eliciting an endogenous SFK-dependent kinase activity, as elucidated by the inhibitory effect of PP2 (lanes 4 and 6). This effect was dramatically enhanced by the co-transfection of both proteins (lanes 3 and 5 vs lane 7), further supporting the model of interaction inferred from the in vitro data. Notably, Lyn, both endogenous and transfected, was detected inside purified mitochondria only when p13 was present (Figure 7A, right panel, lanes 5-8 vs 1-4), clearly paralleling the level of mitochondrial tyrosine phosphorylation (lanes 5 vs 1 and lane 7 vs 3 ). The relative purity of the mitochondrial fraction was assessed by using antibodies against specific cellular markers.

To examine whether the interaction between Lyn and p13 occurred according to the mechanisms previously identified in vitro and whether a stable complex persisted within mitochondria in cultured cells, p13 was immunoprecipitated from the mitochondrial lysates of HeLa cells transfected with expression vectors for Lyn and p13, or with both empty vectors. As shown in Figure 7B, Lyn co-immunoprecipitated with p13 and the GST-Lyn SH3 domain was able to disrupt the p13/Lyn complex (left panel, lanes 4 vs 3), highlighting a role of Lyn's SH3 domain in the interaction of p13. Moreover, the same mitochondrial lysates were assayed for SFK activity in the absence or presence of the GST-Lyn SH3 domain, demonstrating that Lyn in mitochondria displayed a higher activity when associated with p13, further confirming the activatory role of p13 on SEKs (right panel, bar 3 vs. 1).

To corroborate the biochemical data obtained in HeLa cells with regard to the p13/Lyn interaction and import of Lyn into mitochondria, the subcellular localization of Lyn was analyzed in relation with p13 expression by confocal microscopy. Since the anti-p13 antibody was useless in immunofluorescence assay, we used anti-c-myc to follow p13 cellular localization. The pcDNA3.1 expression vector for $\mathrm{p} 13$, indeed, also contains a myc tag. As shown in Figure 8, we observed that p13 mainly localizes to mitochondria, as visualized by double immunofluorescence staining with anti-Tom20 antibody as mitochondrial marker and anti-c-myc, and that its subcellular distribution was unaltered even upon Lyn co-transfection (Figure 8A, merge). By contrast, overexpressed Lyn was shown to co-localize with Tom20 only when p13 was expressed, indicating that p13 was the driving force for Lyn to be recruited to mitochondria (Figure 8B). Finally, as shown in Figure 8C, p13 and Lyn widely overlap when co-expressed in HeLa cells, supporting the association of the two proteins also in vivo. 


\section{Discussion}

In this work, we demonstrate that $\mathrm{p} 13$, a HTLV-1 accessory protein containing a N-terminal mitochondrial localization signal (MLS), associates with the SH3 domain of SFKs through its Cterminal proline rich motif, forming a stable heterodimer that migrates into mitochondria and confers novel functional properties to the single components of the complex. It is to be underlined that mitochondria only recently have been described as a location for SFKs [7]. In fact, although SFKs have commonly been thought to be located at the inner leaflet of the plasma membrane to relay extracellular cues from different types of transmembrane receptors [1-3], accumulating evidence has been reported for a wider intracellular distribution of this family of protein kinases as well as for peculiar functions of SFKs associated with their distinct intracellular localizations [4-9]. In this regard, post-translational modifications such as palmitoylation, and lately the redox state, have been recognized as crucial factors in driving trafficking and localization of SFKs. In particular, three modes of SFK trafficking have been proposed according on the palmitoylation state, i) the cycling pathway between plasma membrane and endosomes/lysosomes for non-palmitoylated SFKs [8, 40, 41], ii) the secretory pathway from the Golgi apparatus to the plasma membrane for mono-palmitoylated SFK [8, 42] and iii) the direct plasma membrane-targeting pathway for doubly palmitoylated SFKs [8]. The redox state has been recently demonstrated to profoundly regulate the trafficking of nonpalmitoylated Src as well, with a remarkable shift of this SFK from the plasma membrane to endosomes/lysosomes accompanied by a decrease in enzyme activity under reducing conditions [36]. In addition to post-translational modifications, protein-protein interactions due to the multimodular structure of SFKs have also been implicated in their targeting specific subcellular compartments. Accumulating data show that the SH3 domain, besides modulating the SFK activity by binding the PPII motif of SFKs themselves, is directly implicated in the localization of SFKs to cellular compartments other than the plasma membrane by recognizing specific ligands. An example of this mode of trafficking is given by the interaction between Hck, a SFK highly expressed in macrophages, and $\mathrm{Nef}$, a HIV -1 multifunctional protein, resulting in the activation of Hck and its accumulation to the Golgi apparatus, thereby causing the arrest of the maturation of nascent cytokine receptor Fms [31].

Our data corroborate the notion that SFK' SH3 domain is one of the players involved in directing SFKs themselves to final destinations based upon localization signals present on interacting partners. In fact, p13, known to enter mitochondria through its MLS, behaves analogously to Nef, by virtue of its C-terminal proline rich motif theoretically suitable for binding SH3 domains. In this study, we demonstrate for the first time that p13 associates indifferently with distinct members of the Src family (Src, Fyn, Fgr and Lyn) via SH3 domain/proline rich motif interaction in vitro, hence forming a heterodimer in which the activity of all the SFKs tested are dramatically enhanced (Figure 1 and 2). Importantly, p13 conserves its ability to translocate into isolated mitochondria, concomitantly participating in a stable complex with SFKs, ultimately carrying them into the mitochondrial intermembrane space. Likewise, both biochemical analysis and confocal microscopy provide compelling evidence that Lyn is also detected inside mitochondria when p13 is co-expressed in HeLa cells, and besides associated with p13 (Figure 7 and 8). This data supports the hypothesis that p13 may act as a carrier for SFKs into mitochondria even in living cells. Moreover, the striking elevation in tyrosine phosphorylation observed in either freshly isolated mitochondria in the presence of synthetic p13 or in p13-overexpressing HeLa cells highlights the role of SFKs, as evidenced by the use of the specific SFK inhibitor PP2 (Figure 5A and 7A), confirming the ability of p13 to function as positive modulator of SFKs.

Noteworthy, we observed a similar scenario while investigating the role of SFKs, and in particular of Lyn, in the context of early liver regeneration, assessing that Lyn translocates from the plasma membrane to mitochondria, more precisely into the mitochondrial intermembrane space, where it is part of a $230 \mathrm{kDa}$ multiprotein complex [33]. It has been only recently demonstrated that this complex, similar to the results shown in the present study, is disrupted by 
the GST-Lyn SH3 domain, in agreement with the model herein proposed. Furthermore, we also showed that Lyn taking part in the multiprotein complex protected the structural and functional integrity as well as the bioenergetic competence of mitochondria by contrasting the potentially harmful effects resulting from ROS elevation and $\mathrm{Ca}^{2+}$ overload, which would fatally lead to cell death (Tibaldi et al, unpublished data).

An experimental setting that exploits p13 as a Trojan horse for SFKs might provide a useful model to elucidate the role of SFKs themselves within mitochondria and how tyrosine phosphorylation influences mitochondrial physiology. In this regard, it is worthwhile to remember that functional studies on isolated mitochondria with full-length synthetic p 13 showed that this protein inserts itself into the inner mitochondrial membrane, thereby inducing an inward $\mathrm{K}^{+}$current with a drop in $\Delta \Psi_{\mathrm{m}}$ and activation of the electron transport chain accompanied by increased mitochondrial ROS production $[34,35]$. In contrast, as highlighted by our results, the $\mathrm{SFK} / \mathrm{p} 13$ complex is still taken up by these organelles, but p13 is unable to target the inner mitochondrial membrane and to perturb $\Delta \Psi_{\mathrm{m}}$. These observations are in agreement with studies that recognize a scaffolding role for SFKs mediated by the SH3 domain, in our hands resulting in impairment of the activity of p13, indicating a non-catalytic function of SFKs [42-46]. Importantly, we note that this property of SFKs does not prove detrimental to their catalytic action, which instead was remarkably increased upon interaction with $\mathrm{p} 13$, suggesting that the catalytic and non-catalytic function might not be mutually exclusive, as sometimes reported in the literature [46], but even be independent or synergistic, and potentially taking part in pathophysiological conditions.

In summary, the SFK/p13 interaction and the resulting effects described above lead us to hypothesize a mechanism by which the transfer of SFKs to different cellular districts, mediated by the SH3 domain and directed by the localization signals of interacting proteins, may exert a more general action in the cell fate by modifying the phosphorylation state and hence the function of key substrates resident in the targeted cellular compartments.

\section{Acknowledgements}

We would like to thank Luc Willems (Gembloux, Belgium) for kindly providing pcDNA3.1/myc-His C/p13.

\section{Funding}

This work has been funded by a grant to A.M.Brunati from Fondazione CARIPARO (Progetto di Eccellenza 2008). 


\section{References}

1. Thomas, S.M. and Brugge, J.S. (1997) Cellular functions regulated by Src family kinases. Annu. Rev. Cell. Dev. Biol. 13, 513-609

2. Parsons, S.J. and Parsons, J.T. (2004) Src family kinases, key regulators of signal transduction. Oncogene 18, 7906-7909

3. Engen, J.R., Wales, T.E., Hochrein, J.M., Meyn, M.A. 3rd, Banu Ozkan, S., Bahar, I. and Smithgall, T.E. (2008) Structure and dynamic regulation of Src-family kinases. Cell Mol. Life Sci. 65, 3058-3073

4. Mohn, H., LeCabec, V., Fischer, S. and Maridonneau-Parini, I. (1995) The src-family protein-tyrosine kinase $\mathrm{p} 59^{\text {hck }}$ is located on the secretory granules in human neutrophils and translocates towards the phagosome during cell activation. Biochem. J. 309, 657-665

5. Bard, F., Patel, U., Levy, J.B., Jurdic, P., Horne, W.C. and Baron, R. (2002) Molecular complexes that contain both c-Cbl and c-Src associate with Golgi membranes. Eur. J. Cell. Biol. 81, 26-35

6. Kasahara, K., Nakayama, Y., Ikeda, K., Fukushima, Y., Matsuda, D., Horimoto, S. and Yamaguchi, N. (2004) Trafficking of Lyn through the Golgi caveolin involves the charged residues on $\alpha \mathrm{E}$ and $\alpha \mathrm{I}$ helices in the kinase domain. J. Cell. Biol. 165, 641-652

7. Salvi, M., Brunati, A.M. and Toninello, A. (2005)yrosine phosphorylation in mitochondria: a new frontier in mitochondrial signalling. Free Radic. Biol. Med. 38, 1267-1277

8. Sato, I., Obata, Y., Kasahara, K., Nakayama, Y., Fukumoto, Y., Yamasaki, T., Yokoyama, K.K., Saito, T. and Yamaguchi, N. (2009) Differential trafficking of Src, Lyn, Yes and Fyn is specified by the state of palmitoylation in the SH4 domain. J. Cell Sci. 122, 965-975

9. Frasson, M., Vitadello, M., Brunati, A.M., La Rocca, N., Tibaldi, E., Pinna, L.A., Gorza, L. and Donella-Deana, A. (2009) Grp94 is Tyr-phosphorylated by Fyn in the lumen of the endoplasmic reticulum and translocates to Golgi in differentiating myoblasts. Biochim. Biophys. Acta 1793, 239-252

10. Williams, J. C., Wierenga, R. K., Saraste, M. (1998) Insights into Src kinase functions: structural comparisons. Trends Biochem Sci. 23: 179-184

11. Chong, Y.P., Ia, K.K., Mulhern, T.D. and Cheng, H.C.(2005) Endogenous and synthetic inhibitors of the Src-family protein tyrosine kinases. Biochim. Biophys. Acta 1754, 210-220

12. Sicheri, F., Moarefi, I. and Kuriyan, J. (1997) Crystal structure of the Src family tyrosine kinase Hck. Nature 385, 602-609

13. Ingley, E.(2008) Src family kinases: regulation of their activities, levels and identification of new pathways. Biochim. Biophys. Acta 1784, 56-65

14. Wang, D., Esselman, W.J. and Cole, P.A. (2002) Substrate conformational restriction and CD45-catalyzed dephosphorylation of tail tyrosine-phosphorylated Src protein. J. Biol. Chem. 277, 40428-40433

15. Boonyaratanakornkit, V., Scott, M.P., Ribon, V., Sherman, L., Anderson, S.M., Maller, J.L., Miller, W.T. and Edwards, D.P. (2001) Progesterone receptor contains a proline-rich motif that directly interacts with SH3 domains and activates c-Src family tyrosine kinases. Mol. Cell 8, 269-280

16. Pellicena, P. and Miller, W.T. (2001) Processive phosphorylation of p130Cas by Src depends on SH3-polyproline interactions. J. Biol. Chem. 276, 28190-28196

17. Moarefi, I., LaFevre-Bernt, M., Sicheri, F., Huse, M., Lee, C.H., Kuriyan, J. and Miller, W.T. (1997) Activation of the Src-family tyrosine kinase Hck by SH3 domain displacement. Nature 385, 650-653

18. Trible, R.P., Emert-Sedlak, L. and Smithgall, T.E. (2006) HIV-1 Nef selectively activates Src Family Kinases Hck, Lyn, and c-Src through direct SH3 domain interaction. J. Biol. Chem. 281, 27029-27038 
19. Lerner, E.C. and Smithgall, T.E. (2002) SH3-dependent stimulation of Src-family kinase autophosphorylation without tail release from the SH2 domain in vivo. Nat. Struct. Biol. 9, 365-369

20. Porter, M., Schindler, T., Kuriyan, J. and Miller, W.T. (2000) Reciprocal regulation of Hck activity by phosphorylation of $\operatorname{Tyr}(527)$ and $\operatorname{Tyr}(416)$. Effect of introducing a high affinity intramolecular SH2 ligand. J. Biol. Chem. 275, 2721-2726

21. Bauer, F., Schweimer, K., Meiselbach, H., Hoffmann, S., Rösch, P. and Sticht, H. (2005) Structural characterization of Lyn-SH3 domain in complex with a herpesviral protein reveals an extended recognition motif that enhances binding affinity. Protein Sci. 14, 2487-2498

22. Liang, Y. and Roizman, B. (2006) State and role of SRC family kinases in replication of herpes simplex virus 1. J. Virol. 80, 3349-3359

23. Shelton, H. and Harris, M. (2008) Hepatitis C virus NS5A protein binds the SH3 domain of the Fyn tyrosine kinase with high affinity: mutagenic analysis of residues within the SH3 domain that contribute to the interaction. Virol. J. 11, 5-24

24. Cho, N.H., Choi, Y.K. and Choi, J.K. (2008) Multi-transmembrane protein K15 of Kaposi's sarcoma-associated herpesvirus targets Lyn kinase in the membrane raft and induces NFAT/AP1 activities. Exp. Mol. Med. 40, 565-573

25. Solheim, S.A., Torgersen, K.M., Taskén, K. and Berge, T. (2008) Regulation of FynT function by dual domain docking on PAG/Cbp. J. Biol. Chem. 283, 2773-2783

26. Chae, Y.K., Woo, J., Kim, M.J., Kang, S.K., Kim, M.S., Lee, J., Lee, S.K., Gong, G., Kim, Y.H., Soria, J.C., Jang, S.J., Sidransky, D. and Moon, C. (2008) Expression of aquaporin 5 (AQP5) promotes tumor invasion in human non small cell lung cancer. PLoS One 3, e2162

27. Samuels, A.L., Klinken, S.P. and Ingley, E. (2009) Liar, a novel Lyn-binding nuclear/cytoplasmic shuttling protein that influences erythropoietin-induced differentiation. Blood 113, 3845-3856

28. Hammond, S., Wagenknecht-Wiesner, A., Veatch, S.L., Holowka, D. and Baird, B. (2009) Roles for SH2 and SH3 domains in Lyn kinase association with activated FcepsilonRI in RBL mast cells revealed by patterned surface analysis. J. Struct. Biol. 168, 161-167

29. Honda, Z., Suzuki, T. and Honda, H. (2009) Identification of CENP-V as a novel microtubule-associating molecule that activates Src family kinases through SH3 domain interaction. Genes Cells 14, 1383-1394

30. Xi, G., Shen, X. and Clemmons, D.R. (2010) p66shc inhibits insulin-like growth factor-I signaling via direct binding to Src through its polyproline and Src homology 2 domains, resulting in impairment of Src kinase activation. J. Biol. Chem. 285, 6937-6951

31. Trentin, L., Frasson, M., Donella-Deana, A., Frezzato, F., Pagano, M.A., Tibaldi, E., Gattazzo, C., Zambello, R., Semenzato, G. and Brunati, A.M. (2008) Geldanamycin-induced Lyn dissociation from aberrant Hsp90-stabilized cytosolic complex is an early event in apoptotic mechanisms in B-chronic lymphocytic leukemia. Blood 112, 4665-4674

32. Hassan, R., Suzu, S., Hiyoshi, M., Takahashi-Makise, N., Ueno, T., Agatsuma, T., Akari, H., Komano, J., Takebe, Y., Motoyoshi, K. and Okada, S. (2009) Dys-regulated activation of a Src tyrosine kinase Hck at the Golgi disturbs N-glycosylation of a cytokine receptor Fms. J. Cell. Physiol. 221, 458-468

33. Gringeri, E., Carraro, A., Tibaldi, E., D'Amico, F.E., Mancon, M., Toninello, A., Pagano, M.A., Vio, C., Cillo, U. and Brunati, A.M. (2009) Lyn-mediated mitochondrial tyrosine phosphorylation is required to preserve mitochondrial integrity in early liver regeneration. Biochem. J. 425, 401-412

34. Silic-Benussi, M., Biasiotto, R., Andresen, V., Franchini, G., D'Agostino, D.M. and Ciminale, V. (2010) HTLV-1 p13, a small protein with a busy agenda. Mol. Aspects Med. 31: 350-358.

35. Silic-Benussi, M., Cannizzaro, E., Venerando, A., Cavallari, I., Petronilli, V., La Rocca, N., Marin, O., Chieco-Bianchi, L., Di Lisa, F., D'Agostino, D.M., Bernardi, P. and Ciminale, V. (2009) Modulation of mitochondrial $\mathrm{K}(+)$ permeability and reactive oxygen species 
production by the p13 protein of human T-cell leukemia virus type 1. Biochim. Biophys. Acta 1787, 947-954

36. Krasnowska, E.K., Pittaluga, E., Brunati, A.M., Brunelli, R., Costa, G., De Spirito, M., Serafino, A., Ursini, F. and Parasassi, T. (2008) N-acetyl-1-cysteine fosters inactivation and transfer to endolysosomes of c-Src. Free Radic. Biol. Med. 45, 1566-1572

37. Kamo, N., Muratsugu, M., Hongoh, R., Kobatake, Y. (1979) Membrane potential of mitochondria measured with an electrode sensitive to tetraphenyl phosphonium and relationship between proton electrochemical potential and phosphorylation potential in steady state. J Membr Biol. 49: 105-121.

38. Jensen, B. D., Gunter, K.K., Gunter, T. E. (1986) The efficiencies of the component steps of oxidative phosphorylation. II. Experimental determination of the efficiencies in mitochondria and examination of the equivalence of membrane potential and $\mathrm{pH}$ gradient in phosphorylation. Arch Biochem Biophys. 248: 305-323.

39. Lefèbvre L, Vanderplasschen A, Ciminale V, Heremans H, Dangoisse O, Jauniaux JC, Toussaint JF, Zelnik V, Burny A, Kettmann R, Willems L. (2002) Oncoviral bovine leukemia virus G4 and human T-cell leukemia virus type 1 p13(II) accessory proteins interact with farnesyl pyrophosphate synthetase. J Virol. 76:1400-1414.

40. Silic-Benussi, M., Cavallari, I., Vajente, N., Vidali, S., Chieco-Bianchi, L., Di Lisa, F., Saggioro, D., D'Agostino, D.M. and Ciminale, V. (2010) Redox regulation of T-cell turnover by the 13 protein of human T-cell leukemia virus type 1: distinct effects in primary versus transformed cells. Blood 116, 54-62

41. Kasahara, K., Nakayama, Y., Kihara, A., Matsuda, D., Ikeda, K., Kuga, T., Fukumoto, Y., Igarashi, Y. and Yamaguchi, N. (2007) Rapid trafficking of c-Src, a non-palmitoylated Srcfamily kinase, between the plasma membrane and late endosomes/lysosomes. Exp. Cell. Res. 313, 2651-2666

42. Obata, Y., Fukumoto, Y., Nakayama, Y., Kuga, T., Dohmae, N. and Yamaguchi, N. (2010) The Lyn kinase C-lobe mediates Golgi export of Lyn through conformation-dependent ACSL3 association. J. Cell Sci. doi: 10.1242/jes.066266

43. Kaplan, K.B., Swedlow, J.R., Morgan, D.O. and Varmus H.E. (1995) c-Src enhances the spreading of src-/- fibroblasts on fibronectin by a kinase-independent mechanism. Genes Dev. 9, 1505-1517

44. Schwartzberg, P.L., Xing, L., Hoffmann, O., Lowell, C.A., Garrett, L., Boyce, B.F. and Varmus, H.E. (1997) Rescue of osteoclast function by transgenic expression of kinasedeficient Src in src-/- mutant mice. Genes Dev. 11, 2835-2844

45. Brunton, V.G., Avizienyte, E., Fincham, V.J., Serrels, B., Metcalf, C.A. 3rd, Sawyer, T.K. and Frame, M.C. (2005) Identification of Src-specific phosphorylation site on focal adhesion kinase: dissection of the role of $\mathrm{Src} \mathrm{SH} 2$ and catalytic functions and their consequences for tumor cell behaviour. Cancer Res. 65, 1335-1342

46. García-Martínez, J.M., Calcabrini, A., González, L., Martín-Forero, E., Agulló-Ortuño, M.T., Simon, V., Watkin, H., Anderson, S.M., Roche, S. and Martín-Pérez, J. (2010) A noncatalytic function of the Src family tyrosine kinases controls prolactin-induced Jak2 signaling. Cell. Signal. 22:415-426 


\section{Legends}

Figure 1. p13 binds SH3 domain of Src, Fyn, Fgr and Lyn via its proline-rich region

(A) Schematic representation of the sequence and relevant functional motifs of p13. MTS: mitochondrial targeting signal (residues 21-35); TM: transmembrane region (residues 30-40); $\mathrm{H}$ : region with a high flexibility score (residues $42-48$ ); B: predicted $\beta$-sheet hairpin structure (residues 65-75); PRM: proline rich motif (residues 75-84). (B) $0.1 \mu \mathrm{g}$ of Src, Fyn, Fgr, Lyn and BSA, the latter used as irrelevant control protein, were subjected to SDS-PAGE and transferred onto nitrocellulose membranes. p13, in the absence or presence of p13 [61-87], was then overlaid on the membranes and probed with anti-p13 antibody. Molecular mass of protein standards are indicated in the middle. (C) $0.2 \mu \mathrm{g}$ of p13 were incubated with $0.1 \mu \mathrm{g}$ of each single SFK in the absence or presence of p13[61-87] or GST-Lyn SH3 domain, alternatively, for 10 min at $30{ }^{\circ} \mathrm{C}$. The subsequent immunoprecipitation was performed with anti-p13 antibody or with specific antibodies against each single SFK. Immunocomplexes were then probed with antibodies to each single SFK or p13, alternatively.

Figure 2. p13 and p13[61-87] act as a positive modulator of Src, Fyn, Fgr and Lyn

(A) Tyrosine kinase activity of Src, Fyn, Fgr and Lyn was tested on the Src-specific peptide substrate cdc2(6-20) in the absence (lane 1) or presence of increasing concentrations of $p 13$ (lanes 2-5) or p13[61-87] (lanes 6-9) alternatively supplemented with the GST-Lyn SH3 domain (lanes 4-5 and 8-10) as described in the Experimental section. Data are expressed as means \pm SD from three separate experiments.**: $p<0.001$ and $*: p<0.05$. (B) Elution profile of activity on Src-specific peptide substrate cdc2(6-20) of Lyn (top panel), Lyn plus p13 (medium panel), and Lyn plus p13 supplemented with GST-Lyn/SH3 domain (bottom panel), obtained form a Superdex 75 HR column as described in the Experimental section. Downward arrows indicate the position of molecular weight standards on Superdex $75 \mathrm{HR}$ column: BSA (66 kDa), Ovalbumin (43 kDa), Chymotrypsinogen (26 kDa) and Lysozyme (14.5 kDa).

\section{Figure 3. p13 acts as a carrier of Src and Lyn for mitochondrial import}

(A) $50 \mu \mathrm{g}$ of RLM were incubated with $\mathrm{p} 13$ and/or Src in the absence or presence of the GSTLyn SH3 domain, respectively. Afterwards, mitochondria were spun down and the resulting fractions, mitochondria $(\mathrm{M})$ and surnatant $(\mathrm{S})$, were subjected to Western blot analysis with antiSrc and subsequently with anti-p13 antibodies. The membranes were re-probed with antiaconitase antibody as loading control. (B) $50 \mu \mathrm{g}$ of RLM were incubated with p13 and/or Lyn in the absence or presence of the GST-Lyn SH3 domain, respectively, and treated as described in (A). The figure is representative of four experiments performed in triplicate.

Figure 4. p13 and Lyn are detected as component of a soluble complex in the intermembrane space of isolated mitochondria

RLM were incubated with p13 only (left panels) or in the presence of Lyn (right panels) and treated as described below. (A) RLM were incubated in the absence or presence of proteinase K (PK) and Triton X-100 (TX-100) according to the Experimental section. Aliquots of the mitochondrial lysate were subjected to Western blot analysis with anti-Lyn, anti-p13, anti-AIF and anti-aconitase antibodies, respectively. (B) RLM were subjected to treatment to obtain mitochondrial membranes and soluble fractions as described in the Experimental section. Intact mitochondria (Mit.), mitochondrial membranes and soluble fractions were subjected to Western blot analysis with anti-Lyn, anti-p13, anti-AIF and anti-aconitase antibodies, respectively. (C) RLM were incubated in the presence of increasing concentrations of digitonin. After each treatment the samples were spun down to separate pellet $(\mathrm{P})$ from soluble fraction $(\mathrm{S})$. Aliquots of such fractions after differential digitonin treatment were subjected to Western blot analysis with anti-Lyn, anti-p13, anti-AIF and anti-aconitase antibodies, respectively. The figure is representative of four independent experiments performed in triplicate. 


\section{Figure 5. p13-mediated import of Lyn increased tyrosine phosphorylation in isolated} mitochondria

(A) $50 \mu \mathrm{g}$ of RLM were incubated with p13 and/or Lyn in the absence or presence of $1 \mu \mathrm{M}$ PP2. RLM were subsequently spun down and subjected to Western blot analysis with anti-p-Tyr (top panel), anti-Src pY416 (middle panel) and anti-Lyn (bottom panel) antibodies. The molecular weight markers are indicated on the right. (B) $250 \mu \mathrm{g}$ of RLM were incubated with p13 and Lyn. RLM were then spun down and aliquots of $50 \mu \mathrm{g}$ mitochondria were lysed and immunoprecipitated with anti-p13 antibody in the absence or presence of increasing concentrations of GST-Lyn SH3. The immunocomplexes were probed with anti-Lyn and subsequently with anti-p13 antibodies. (C) $250 \mu \mathrm{g}$ of RLM were incubated with p13 and Lyn. After 5 min incubation, mitochondria were spun down and aliquots of $50 \mu \mathrm{g}$ of mitochondria were analyzed for in vitro Lyn activity in the absence or presence of increasing concentrations of GST-Lyn SH3. The figure is representative of four independent experiments.

Figure 6. Interaction between SH3 domain of Lyn and p13 proline rich motif impairs p13 ability to induce a collapse in the inner mitochondrial potential $\left(\Delta \Psi_{\mathrm{m}}\right)$

RLM were incubated in $200 \mathrm{mM}$ sucrose, $10 \mathrm{mM}$ Hepes, $\mathrm{pH} 7.4,5 \mathrm{mM}$ succinate, $1.25 \mu \mathrm{M}$ rotenone, $1 \mathrm{mM}$ sodium phosphate and protease inhibitors in the presence of p13 only or with increasing concentrations of Lyn (A) or GST-Lyn SH3 domain (B). The downward arrows indicate the time-point at which p13 or p13 complex was added. The figure is representative of four independent experiments. $\Delta \mathrm{E}$, electrode potential.

\section{Figure 7. The p13/Lyn complex localizes in mitochondria of p13-transfected Hela cells}

(A) HeLa cells were transfected with expression vectors for Lyn (pCMV6-XL4/Lyn, lanes 3-4 and 7-8), p13 (pcDNA3.1/myc-His C/p13, lanes 5-8), or with both empty vectors (pCMV6-XL4 and pcDNA3.1/myc-His $\mathrm{C}$, lanes 1 and 2 , respectively). $36 \mathrm{~h}$ after transfection cells were treated with $10 \mu \mathrm{M}$ PP2 (lanes 2, 4, 6 and 8) for $12 \mathrm{~h}$. Whole cell lysates (left panels) and whole mitochondrial lysates (right panels) were assayed by Western blot analysis with anti-Lyn, antip13, anti-p-Tyr, anti-LDH (cytosolic marker), anti-calnexin (microsomal marker), anti-lamin (nuclear marker) and anti-aconitase (mitochondrial marker) antibodies respectively. (B) Mitochondrial lysates from HeLa cells transfected with expression vectors for Lyn and p13 (lanes 3 and 4), or with both empty vectors (lanes 1 and 2) were analyzed for in vitro Lyn activity on SFK-specific peptide substrate cdc2(6-20) (right panel) or were immunoprecipitated with anti-p13 antibody (left panel) in the absence (lanes 1 and 3) or presence of GST-Lyn SH3(lanes 2 and 4). The immunocomplexes were probed with anti-Lyn and subsequently with anti-p13 antibodies. The figure is representative of three independent experiments.

\section{Figure 8. Lyn localizes to mitochondria of HeLa cells only upon co-expression of p13}

HeLa cells were transfected with expression vectors for Lyn (pCMV6-XL4/Lyn), p13 (pcDNA3.1/myc-His C/p13), or with both empty vectors. 48 hours post-transfection, cells were fixed, permeabilized and incubated with the indicated antibodies. (A) Cells transfected with p13 only or Lyn and p13 were incubated with anti-c-myc and anti-TOM20 R (mitochondrial marker) antibodies followed by FITC-conjugated anti-mouse secondary antibody (green) and with TRITC-conjugated anti-rabbit secondary antibody (red), respectively. (B) Cells transfected with Lyn only or Lyn and p13 were incubated with anti-Lyn and anti-TOM20 M antibodies, followed by incubation with TRITC-conjugated anti-rabbit secondary antibody (red) and with FITCconjugated anti-mouse secondary antibody (green), respectively. (C) Cells transfected with expression vectors for Lyn, p13 or Lyn/p13 were probed with anti-Lyn and anti-c-myc antibodies, followed by the appropriate secondary antibodies, as described above. Colocalization is visualized by the yellow fluorescence appearing after merging of both signals. The figure is representative of three independent experiments. Scale bar: $10 \mu \mathrm{m}$. 
Fig. 1

\section{A}

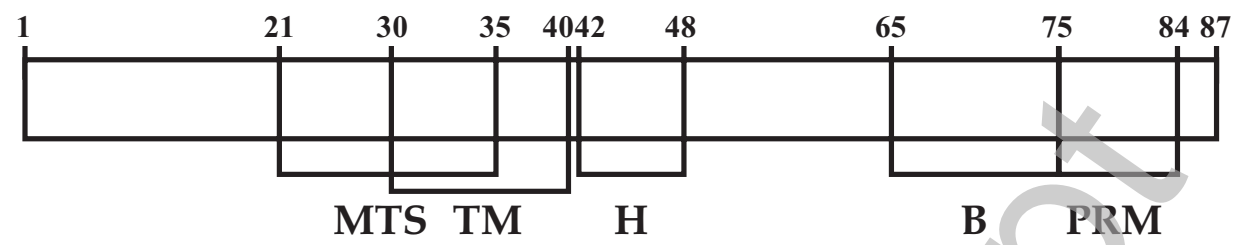

B

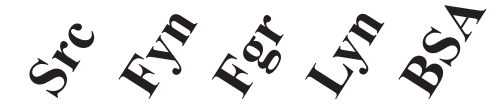

kDa
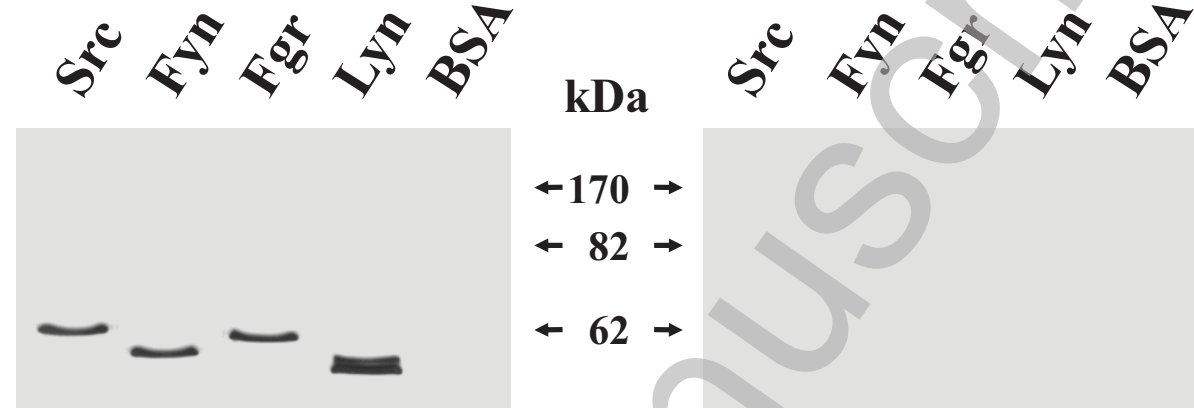

$\leftarrow 170 \rightarrow$

$\leftarrow 82 \rightarrow$

$\leftarrow 62 \rightarrow$

$\leftarrow 47 \rightarrow$

$\leftarrow 36 \rightarrow$

$+25 \rightarrow$

-p13 [61-87]

+ p13 [61-87]

C

Ip: p13

Wb: Src

Wb: p13

\section{Ip: p13}

Wb: Fyn

Wb: p13

Ip: p13

Wb: Fgr

Wb: p13
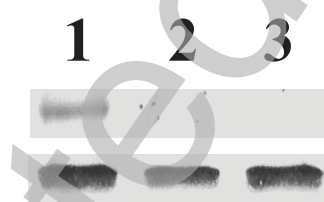

Ip: Src

Wb: p13

Ip: Fyn

Ip: Fgr

Wb: p13

Ip: Lyn

Ip: p13

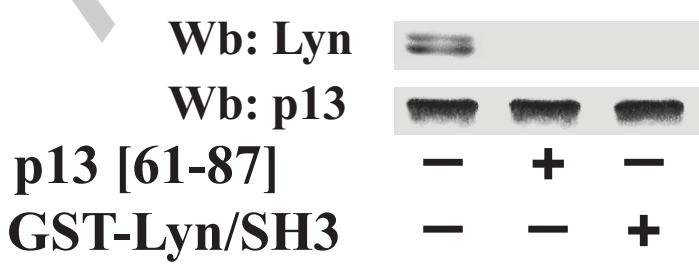

Wb: Src

Wb: p13

Wb: Fyn

Wb: Fgr

$\begin{array}{lll}4 & 5 & 6\end{array}$

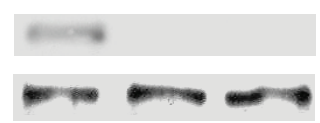

Wb: p13

Wb: Lyn

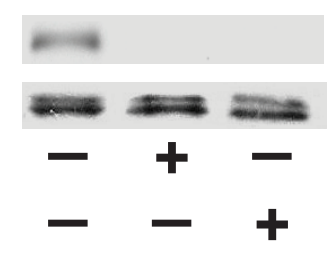


B Biochemical Journal Immediate Publication. Published on 07 Jul 2011 as manuscript BJ20101650

Fig. 2

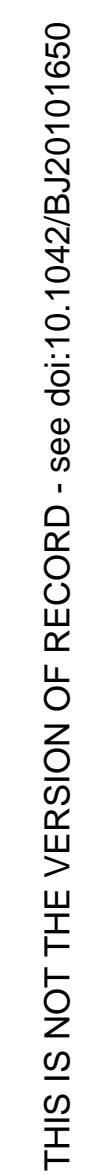

A

Sre
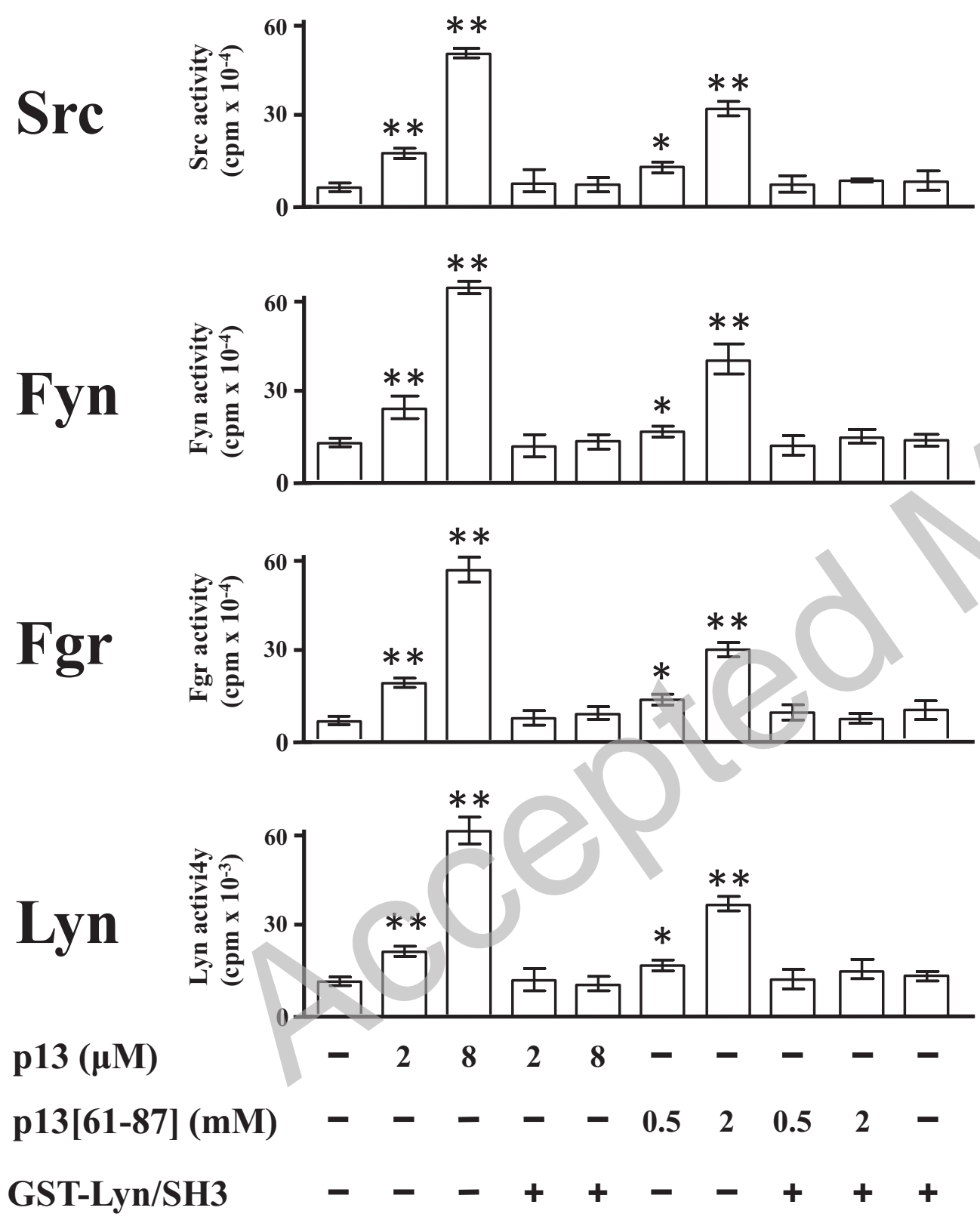

B
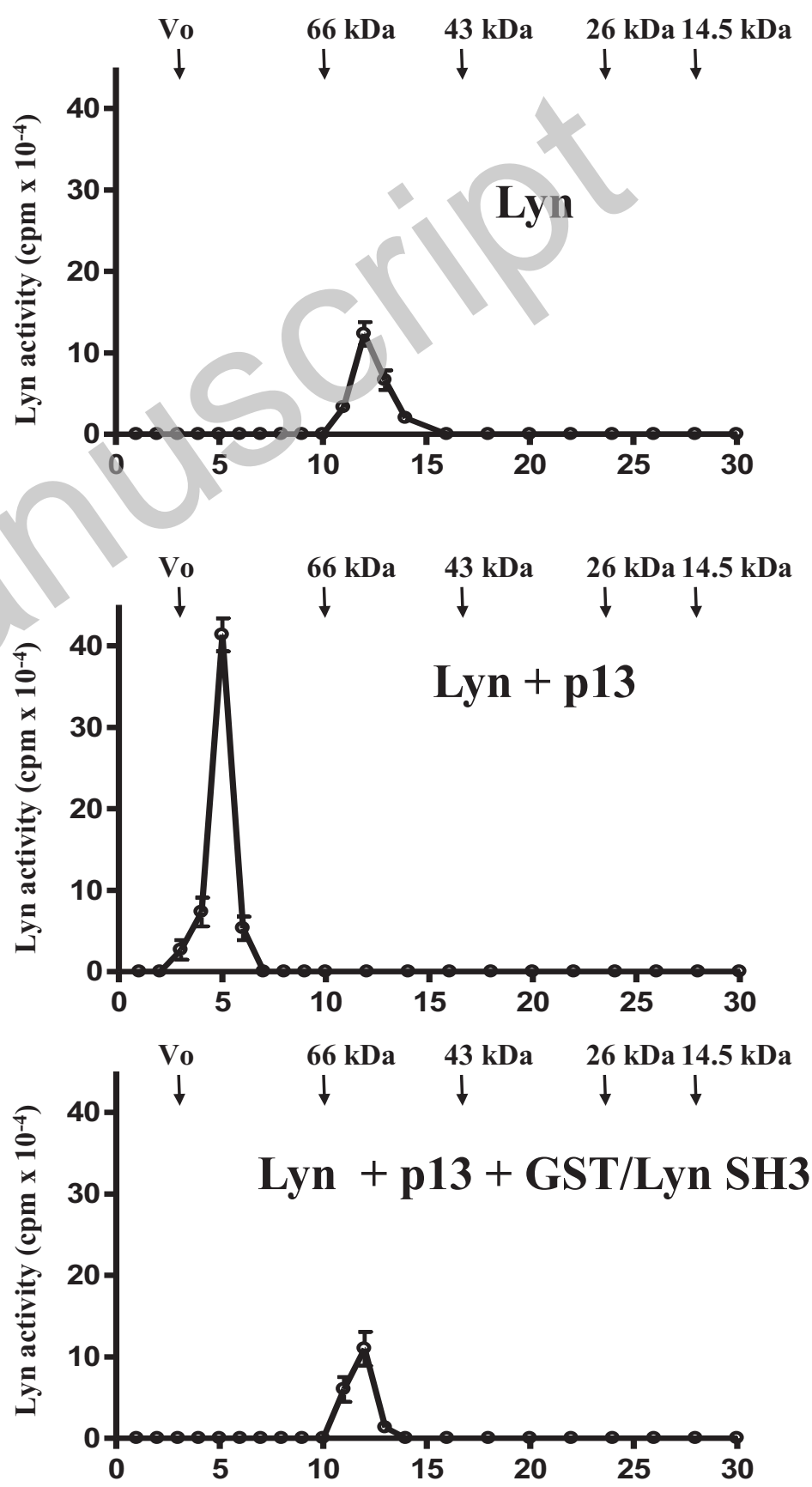

Licenced copy. Copying is not permitted, except with prior permission and as allowed by law. (c) 2011 The Authors Journal compilation ( 22011 Portland Press Limited 
Fig. 3

A

Wb: Src

Wb: p13

Wb: aconitase

$$
\begin{array}{lllllll}
1 & 2 & 3 & 4 & 5 & 6 & 7
\end{array}
$$

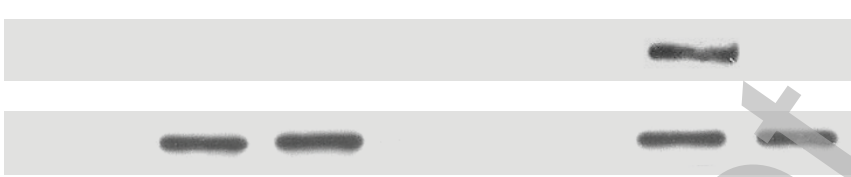

Wb: Src

Wb: p13

Wb: aconitase

Src

$-\quad-+++$

p13

$-++-t+$

GST-Lyn/SH3 - -++-+

B

\section{$\begin{array}{lllllll}1 & 2 & 3 & 4 & 5 & 6 & 7\end{array}$}

Wb: Lyn

Wb: p13

Wb: aconitase

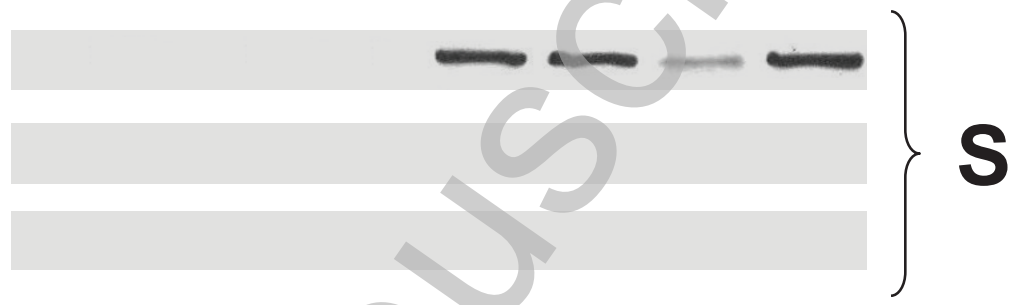

$\mathbf{S}$

M
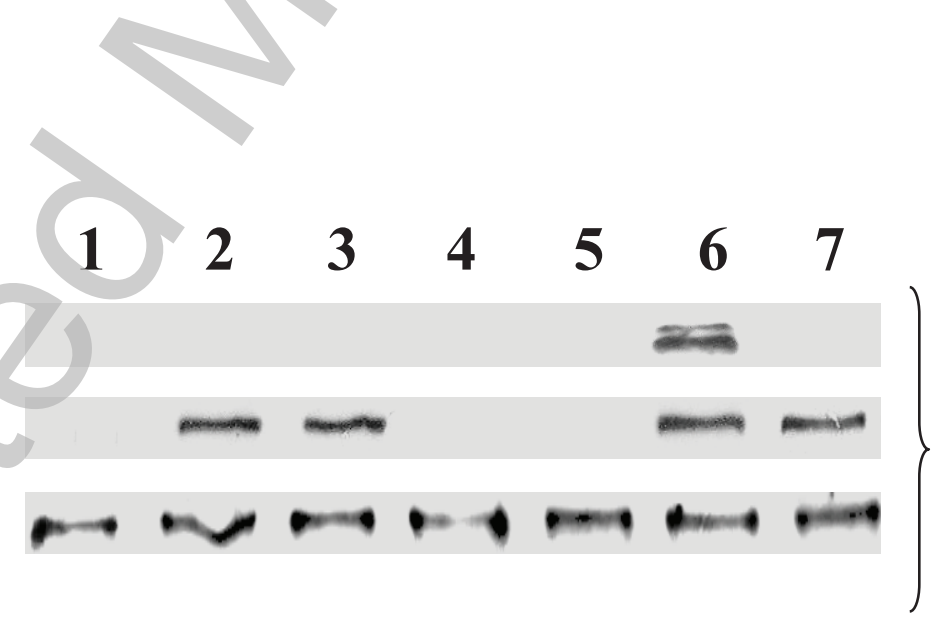

M

Wb: Lyn

Wb: p13

Wb: aconitase

Lyn

$-\quad-++++$

p13

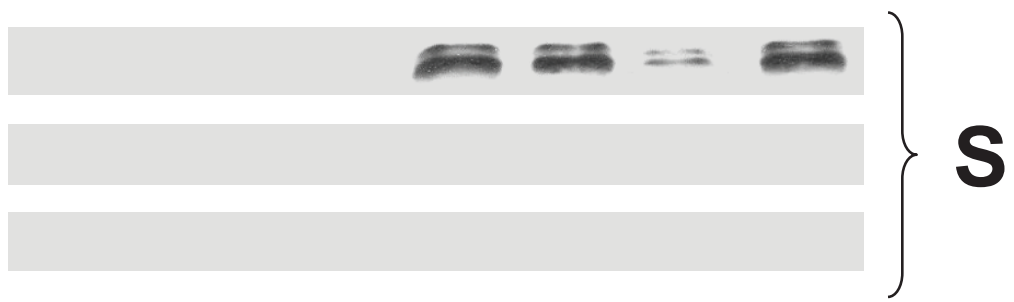

GST-Lyn/SH3 - $-+-+\infty$ 
B Biochemical Journal Immediate Publication. Published on 07 Jul 2011 as manuscript BJ20101650

Fig. 4

A

Mitochondria /p13

PK

TX-100

Wb: Lyn

Wb: p13

Wb: AIF

Wb: aconitase$$
\text { . }
$$

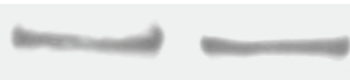

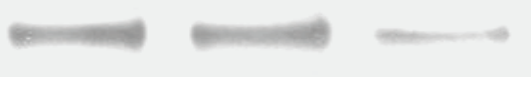

B

\section{Wb: Lyn}

Wb: p13

Wb: AIF

Wb: aconitase
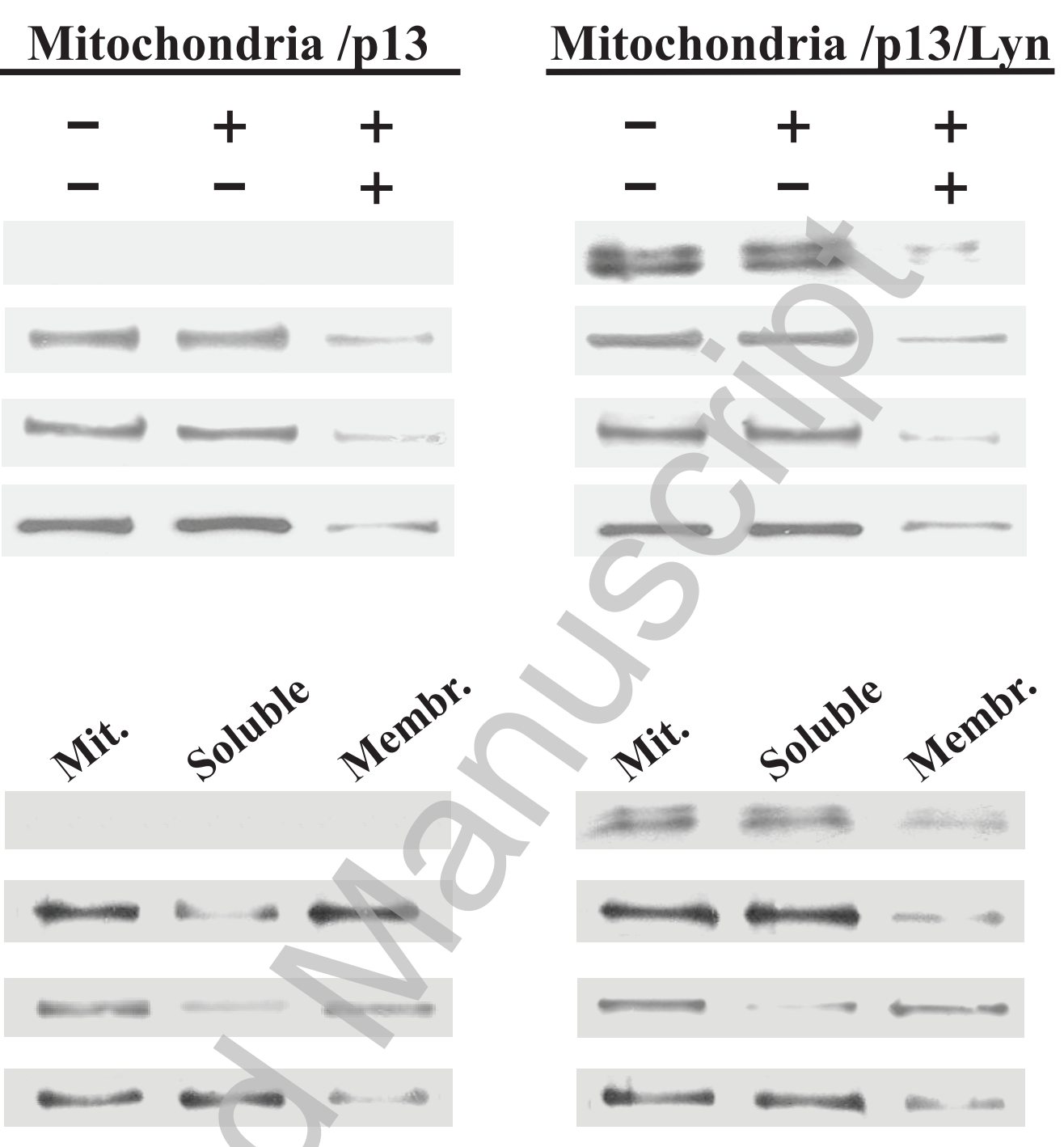

C

$\begin{array}{lllllll}\text { Digitonin }(\mathrm{mg} / \mathrm{ml}) & 0 & 0.1 & 0.2 & 0.4 & 0.6\end{array}$
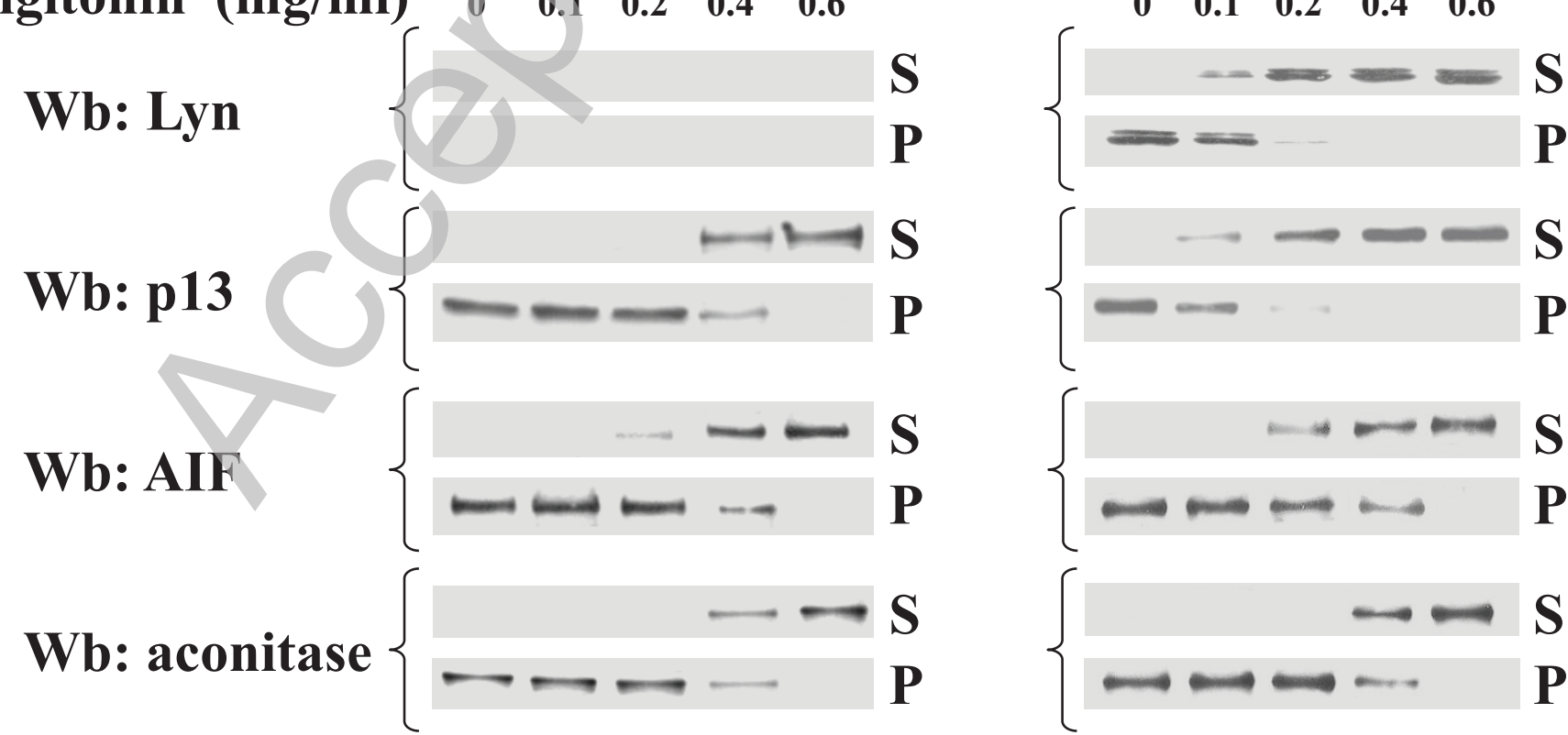

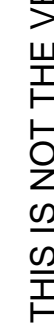
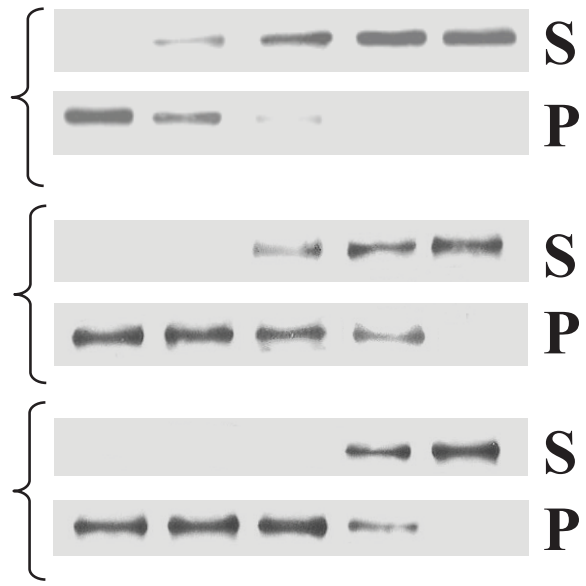

Licenced copy. Copying is not permitted, except with prior permission and as allowed by law. (C) 2011 The Authors Journal compilation (c) 2011 Portland Press Limited 
Fig. 5

A

Wb: p-Tyr

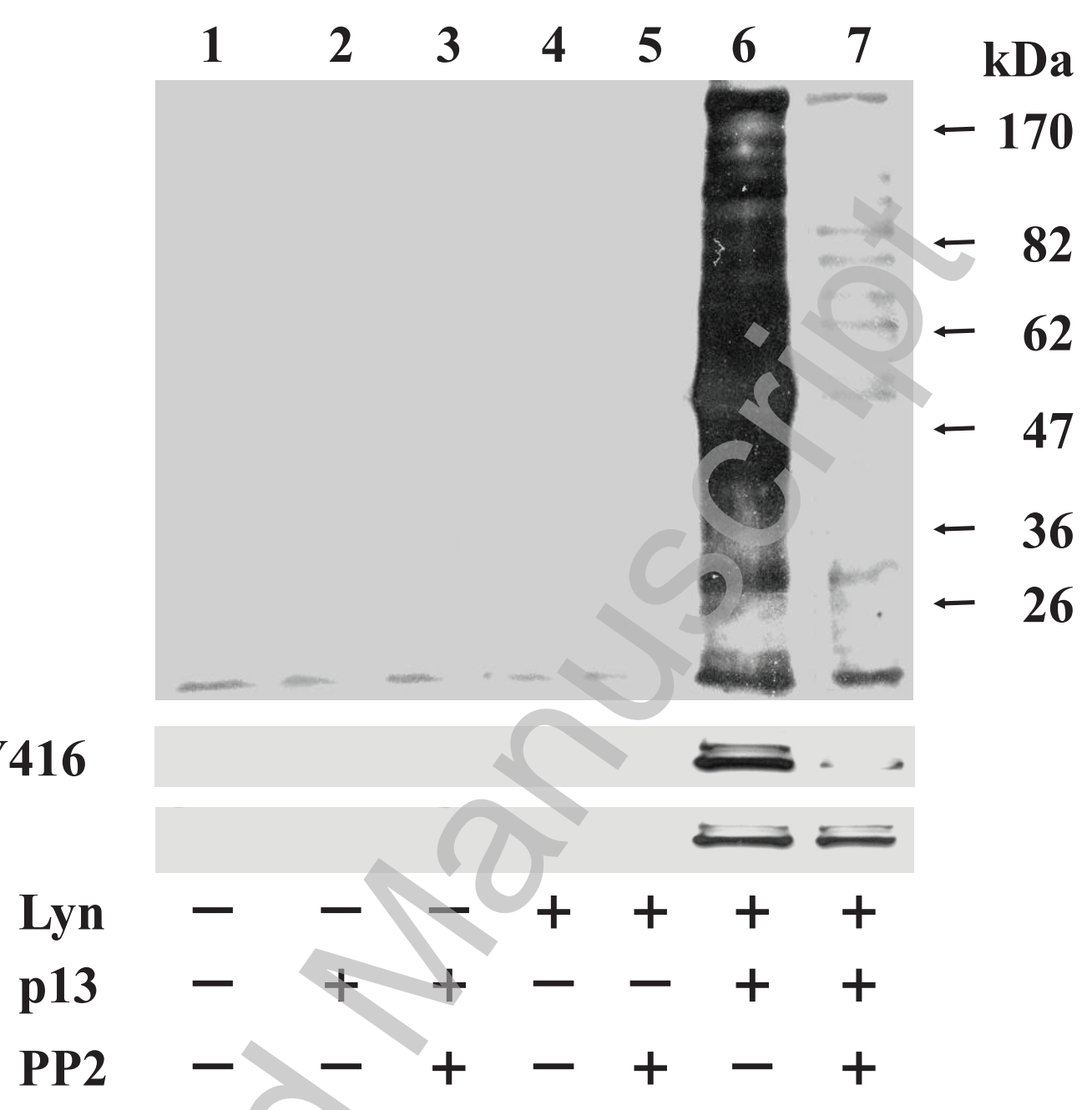

B

Wb: Src pY416

Wb: Lyn

Ip: p13

$\begin{array}{lll}2 & 3 & 4\end{array}$

Wb: Lyn

Wb: $p 13$

GST-Lyn/SH3 (nM)

$\begin{array}{lll}10 & 50 & 250\end{array}$

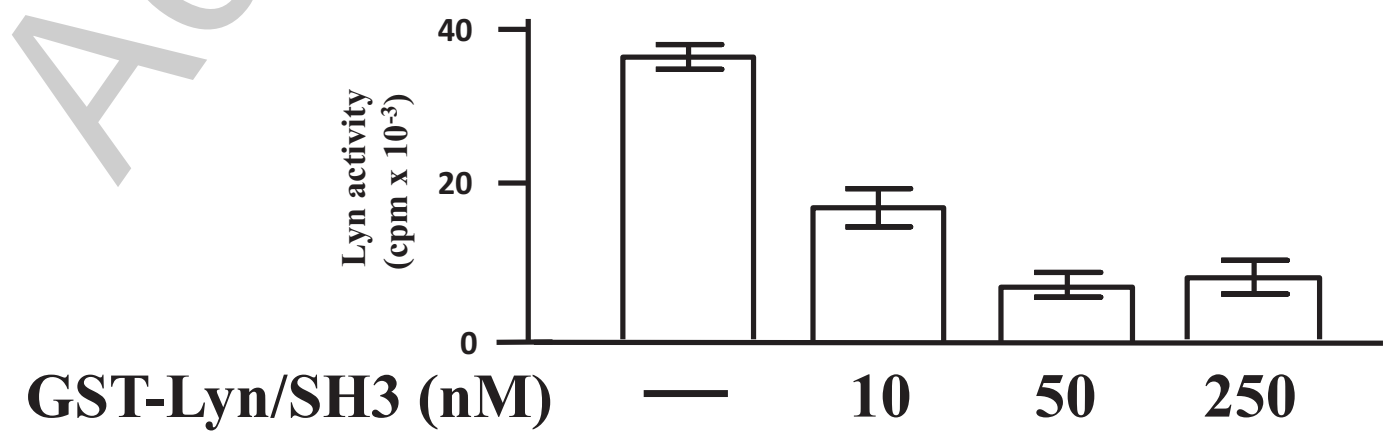

Licenced copy. Copying is not permitted, except with prior permission and as allowed by law. (C) 2011 The Authors Journal compilation (c) 2011 Portland Press Limited 
B Biochemical Journal Immediate Publication. Published on 07 Jul 2011 as manuscript BJ20101650

Fig. 6
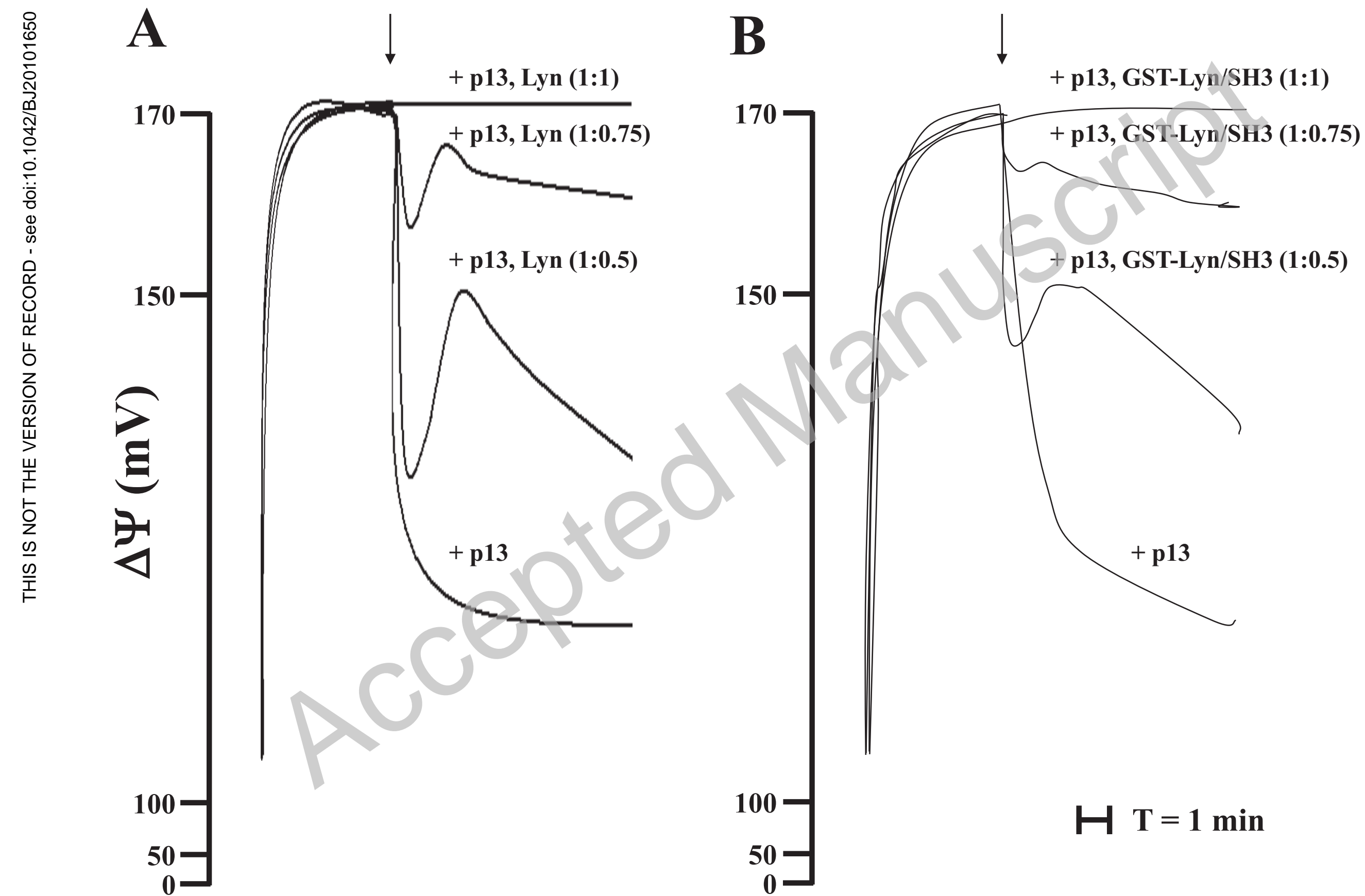

Licenced copy. Copying is not permitted, except with prior permission and as allowed by law. (c) 2011 The Authors Journal compilation @ 2011 Portland Press Limited 
Biochemical Journal Immediate Publication. Published on 07 Jul 2011 as manuscript BJ20101650

Fig. 7

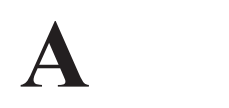

Lysate

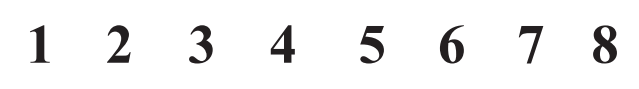

PP2 (10 $\mu M)$

Wb: Lyn

Wb: p13

Wb: p-Tyr

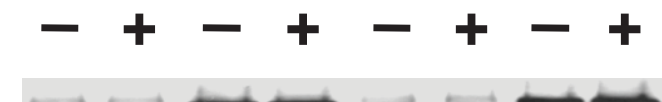

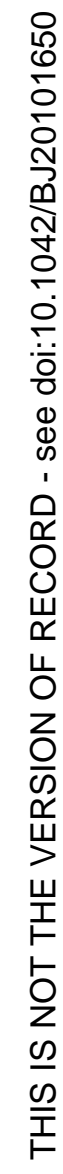

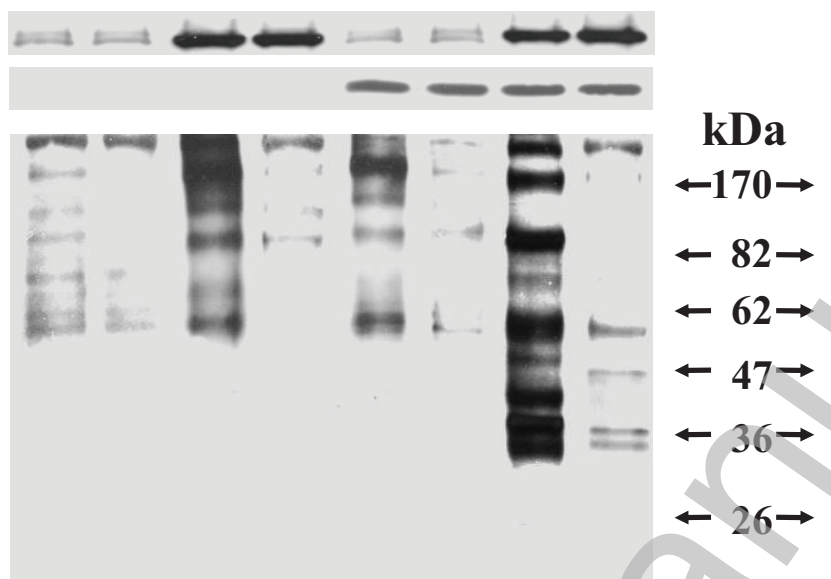

Wb: LDH $\quad-----\cdots--40 \rightarrow$

Wb: calnexin $--\infty-\infty-\infty 5 \rightarrow$

Wb: lamin $\quad-\cdots-\infty-\infty-\infty$

Wb: aconitase $-\longrightarrow-\leftarrow-\square-\leftarrow \rightarrow$

B

\section{$\underline{\text { Mitochondria }}$}

Ip: p13

Wb: Lyn

Wb: p13

GST-Lyn/SH3 -+-+
Mitochondria
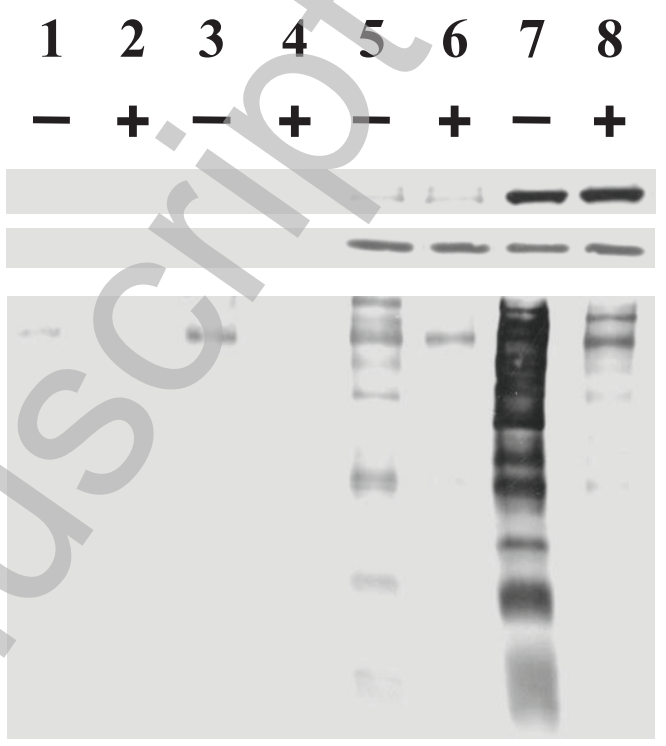
B Biochemical Journal Immediate Publication. Published on 07 Jul 2011 as manuscript BJ20101650

Fig. 8

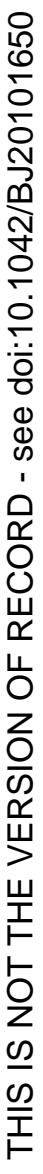

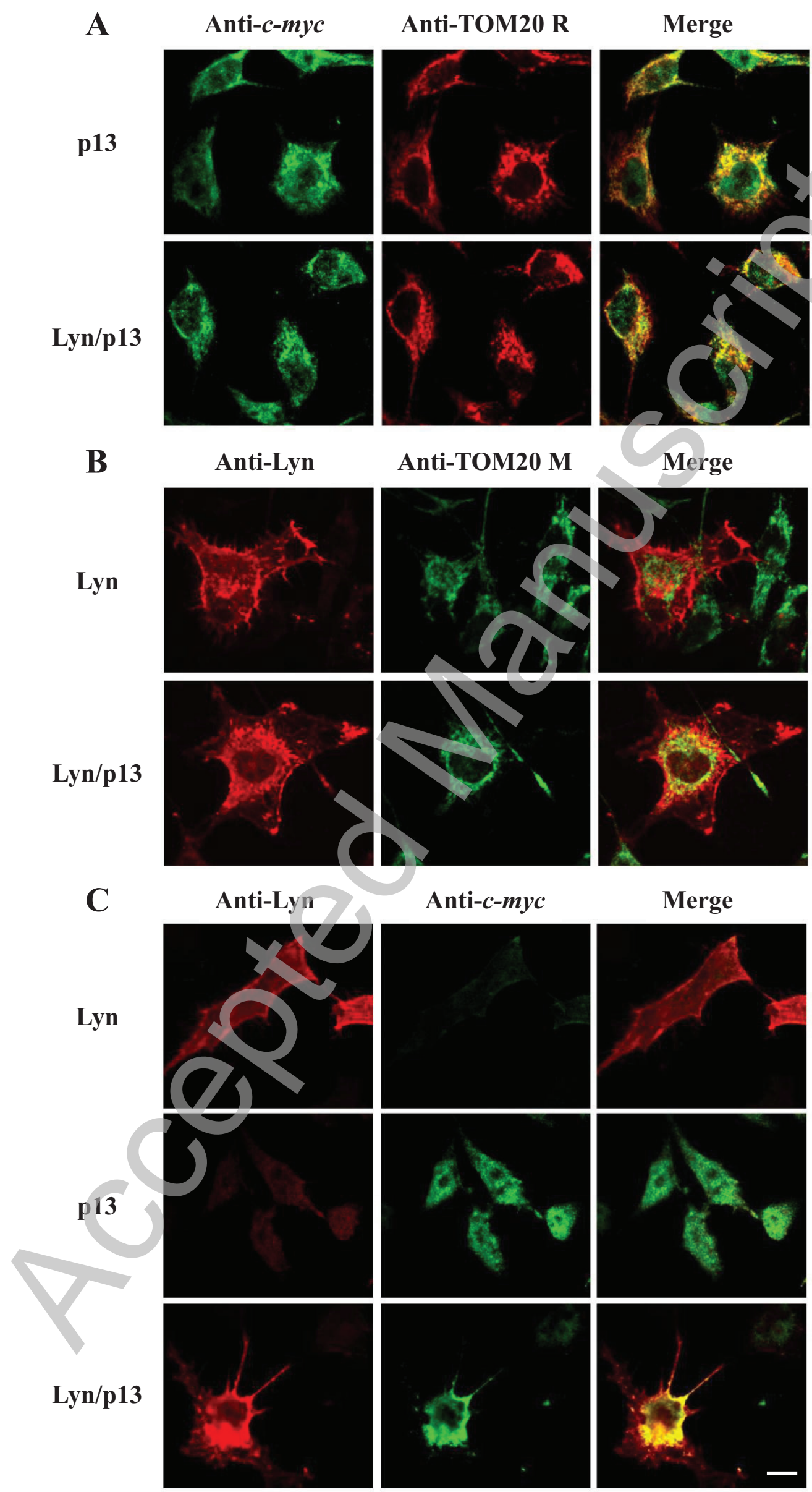

Licenced copy. Copying is not permitted, except with prior permission and as allowed by law. (C) 2011 The Authors Journal compilation (c) 2011 Portland Press Limited 